\title{
Urban Morphology - Different Attributes that Shape Urban Form
}

\author{
Ar. Shanu Raina ${ }^{1}$, Ar. Bhagyalaxmi Madapur ${ }^{2}$ and Dr. Mamatha P Raj ${ }^{3}$ \\ ${ }^{1}$ BMS College of Architecture, Bangalore-560019, India \\ ${ }^{2}$ BMS College of Architecture, Bangalore-560019, India \\ ${ }^{3}$ BMS College of Architecture, Bangalore-560019, India
}

\begin{abstract}
.
Urban morphology in the broadest sense is the resultant of socio-economic as well as cultural processes and refers to the physicality of the urban form. The major morphological factors of cities include natural determinants and manmade determinants. In this paper, core overlapping morphological measures have been critically explored to analyze morphological attributes using Basavanagudi, one of the prominent neighborhoods of Bangalore city, India as a case study. These quantifiable methods can be used as indices by different stakeholders to formulate a framework of different schemes to steer the city towards elevating the quality of urban living.
\end{abstract}

Keywords-Urban morphology, Urban form, morphological measures, morphological attributes, Urban living, Built environment

\section{Introduction}

Urban morphology in the broadest sense is the resultant of socio-economic as well as cultural processes and refers to the physicality of the urban form in terms of its land uses, spatial patterns based on physical infrastructure, block layouts, built environment and urban open and green spaces all of which are considered as part of the historic evolutionary process of development of a particular area of the city. The primary concern of urban morphology is the structure of urban form and the urban form in turn is the result of internal structures of urban areas. The major morphological factors of cities include natural determinants (climate, topography and local materials available for construction) and manmade determinants (involve politics, religions, defence, planning and functioning). The current trends that are yielding vivid patterns of urban form are the result of un-related, un-connected and most importantly un-coordinated attempts practiced by a wide spectrum of people including policy makers, citizens, urban planners, urban designers, architects and engineers. Metropolis, across the world are encountering significant morphology amassing different phases and attributes owing to varied schemes, outlines and primacies of the diverse stake holders while expanding the urban fabric into multitude directions. Every successive socio-political decision and physical uncertainties impose new attributes to the city's spatiality continuing the cycle of morphogenesis. 
Accelerated urban morphology is inevitable as many cities are undergoing urbanization at unprecedented speed, affecting the quality of urban life to a large extent. Spatial extent and physical grain of the city not only morph into different form but also function as altogether new attributes within the existing city fabric. Several physical paradigms can be studied using urban morphological methodologies. These quantifiable methods can be used as indices by planners, designers as well as policy makers to formulate a framework of different schemes to steer the city towards elevating the quality of urban living. In this paper, core overlapping morphological measures such as land use, development regulations, physical and social infrastructure, built form environment, public realm, green/open spaces, user profile - inhabitants and vendors have been critically explored to analyze morphological attributes using Basavanagudi, one of the prominent neighborhoods of Bangalore city, India as a case study.

\section{Bangalore - Mapping the Morphology}

Over the past seventy years, Bangalore, the capital city famously referred as Silicon Valley of India has morphed from being a non-descript town into metropolis. Bangalore, ranked as the most dynamic city in the world adds about 500 families and $80,000 \mathrm{SqM}$ of built up area per day owing to the economic reforms that are accelerating the pace of urbanization. The transformation of the city has been exceptionally marked by several phases of investments/developments in various socio-economic sectors (public and private), remarkable demographic growth as well as flourishing informal economy. Many of the early organizational and planning attempts belonging to that particular time period have been predominately inscribed by various rulers and administrators which readily got absorbed by each consecutive attempt.

Bangalore's morphology corresponds to four noticeable transformative phases:

- The native town (1537 to 1809 )

- Colonial Period (1809 to 1947)- During this period city evolved as evidently two isolated entities; Pete (western part or Native area) and Cantonment (eastern part or British area)

- Science and Industry phase (1947 to 1980)

- Hi-tech phase (1980 to till date)

The emerging city morphology can be spatially categorized into Centers, Corridors, Wedges and Peripheries such as:

- Economic and socio-cultural activity centers

- Mass transit corridors

- Wedges consisting of neighborhoods

- Expanding urban peripheries. 
Bangalore, as a 'ridge and valley settlement' was shaped by the source of water supply and considerations of proper drainage of the soil. Bangalore's morphology is geographically determined as it has a close knit relationship with the physical setting of the site. The geographical and spatial distribution of economic activities (administrative capital of the state, public sector organizations, academic institutions, small to medium scale industries and development of information technology / bio-technology related industries) across various parts of the city reflects its different stages of evolution and the distinctive morphology underlying the socio-spatial contexts.

\section{Basavanagudi Neighborhood - Compatibility amid Diversity}

Basavanagudi, is one of the oldest and historically significant areas of growing metropolitan city of Bangalore. It is named after a huge temple dedicated to bull (Basavanagudi) which is a major religious landmark on the cultural map of Bangalore.

A major epidemic, plague in 1898, forced city administrators to enforce the rules of town planning that emphasized on public health. Basavanagudi was the location of the plague camp. But soon an extension in the form of a layout was planned on 440 acres of dry land and came to be popularly known as Basavanagudi. Several other extensions and new developments such as Chamarajpet, Seshadripuram, Malleshwaram along with Basvanagudi were built strictly according to the grid iron or chess plan and were promoted as 'Model Hygienic Suburbs'. All the blocks were wellspaced and most importantly a heavy downpour would not leave a trace of standing water in the entire neighborhood owing to the well planned block layouts that followed natural drainage system. Basavanagudi extension facilitated built forms to be constructed facing the cardinal points as per the ancient Hindu tradition by following the rectangular design, with boundary roads running North-South and East-West and intermediate roads parallel to them to them (Refer Fig.2). Consideration of the entire neighborhood of Basavanagudi for the analysis of morphology measures is not within the scope of the paper of this length. Hence, an important part of the neighborhood which consists of the main road popularly known as Gandhi Bazaar and the immediate parallel roads along with blocks of this main road have been delineated as the study area (Refer Fig.1 \& 3).
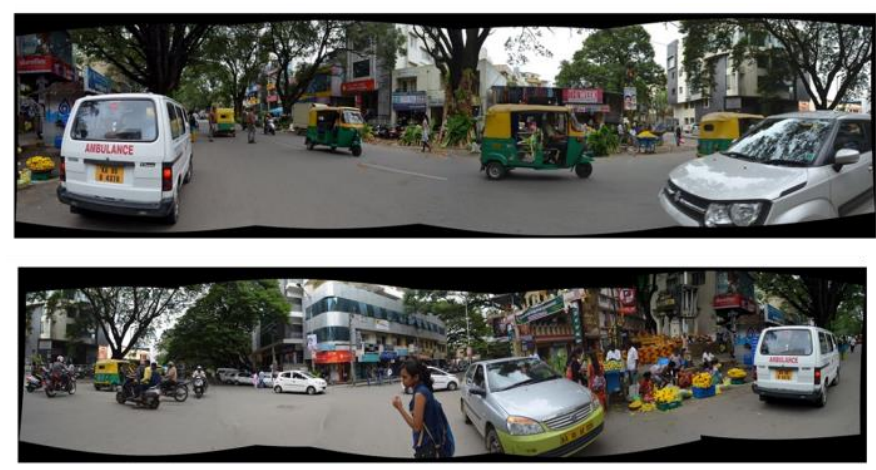

Fig. 1.View of the selected study area (Source: Authors) 
7th International Conference on Research in Science and Technology October $19-21,2018$

Munich - Germany
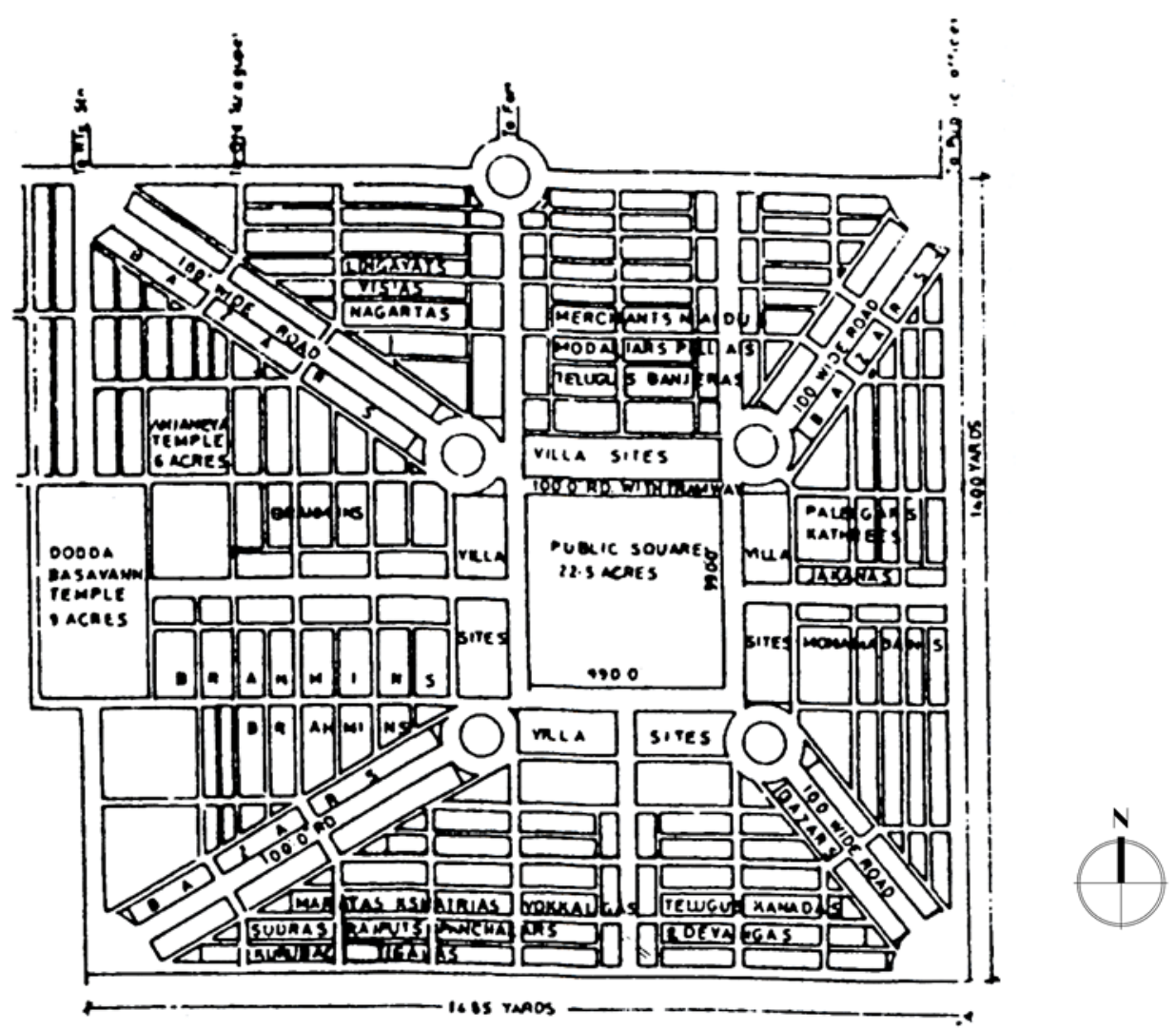

Fig. 2.Plan- Basavanagudi Extension,1894 (Source: Revenue maps, Bangalore)

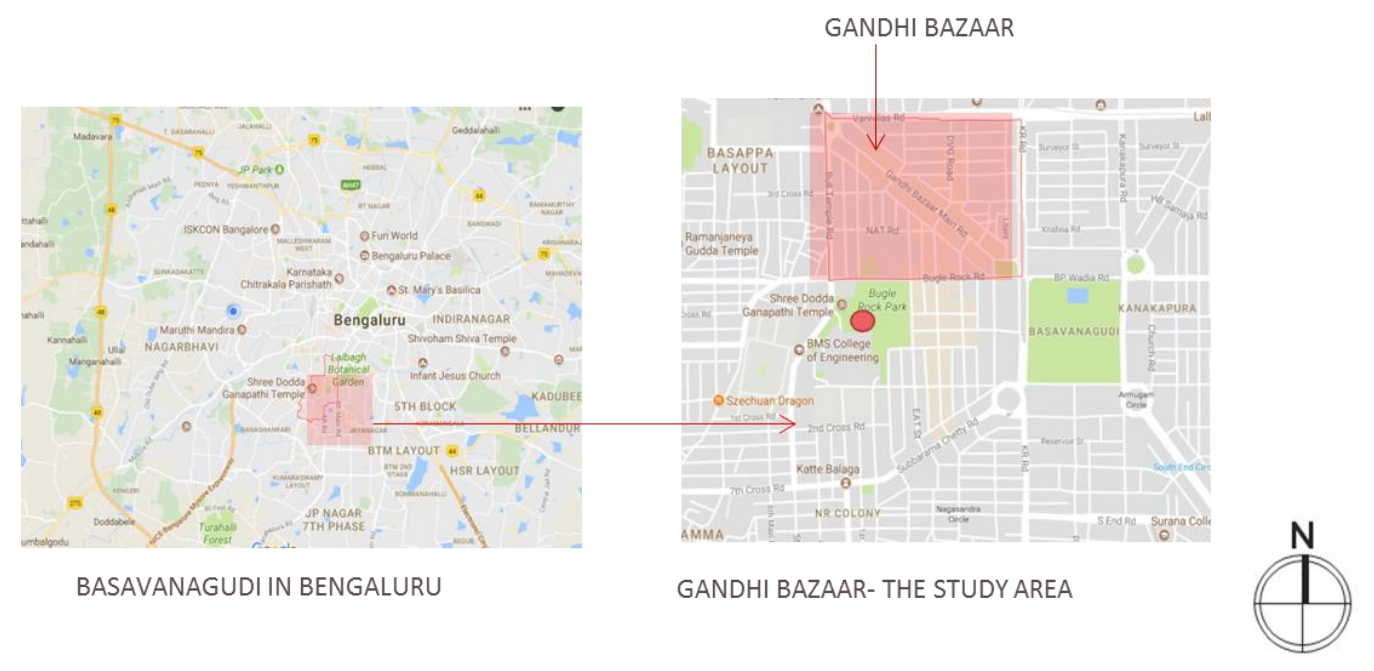

Fig. 3.Location of delineated study area (Source: Google maps and edited by authors)

\subsection{Morphological Synthesis}

In the delineated study area, core overlapping morphological measures such as land use, development regulations, physical and social infrastructure, built form environment, public realm, 
green/open spaces, user profile- inhabitants and vendors have been analyzed to map the morphology and the resulting urban form.

\subsubsection{Land use measure}

Land being the fundamental resource of society involves surface utilization of developed/undeveloped land on the basis of certain compatible characteristics at a specific given time and space for drafting rational planning to allocate spatial arrangement for specific activities. The major land use in the diagonal bazaar is commercial (mainly shops, retail stores and cafés), while the inner neighborhood is predominantly residential. The residential development is gradually rezoned into mixed use (residence \& retail shops or commercial \& public or commercial $\&$ residential).

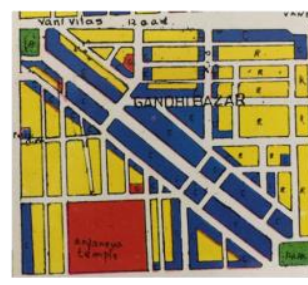

CDP 1995

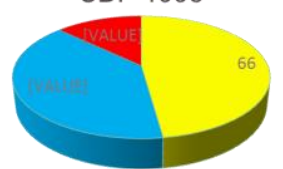

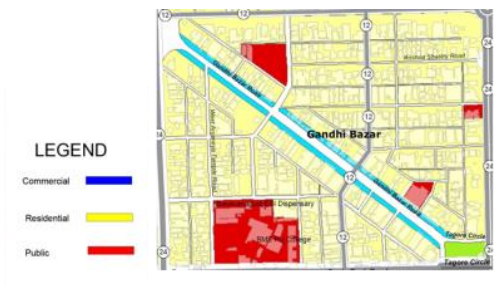

CDP 2015

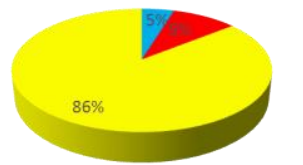

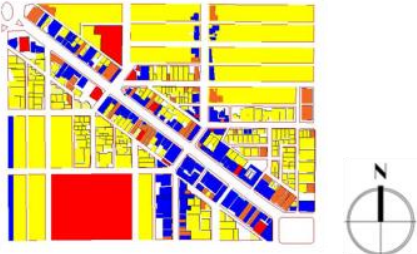

EXISTING

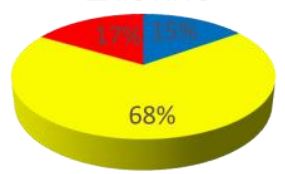

Fig. 4.Proposed and existing land use maps (Source: BDA and edited by authors)

The sub division of the plots is a common phenomenon. Due to many educational institutions in the close proximity the demand for the rental accommodation for students is increasing. The Commercial buildings are located along street edges. The commercial usage compatibility in a predominantly residential neighborhood has not been assessed. This is leading to exploitation of the existing infrastructure and adding to the increased developmental pressure which is evident in the perpetual densification of the area without due consideration for supporting utility networks (Refer Fig. 4 \& 5).

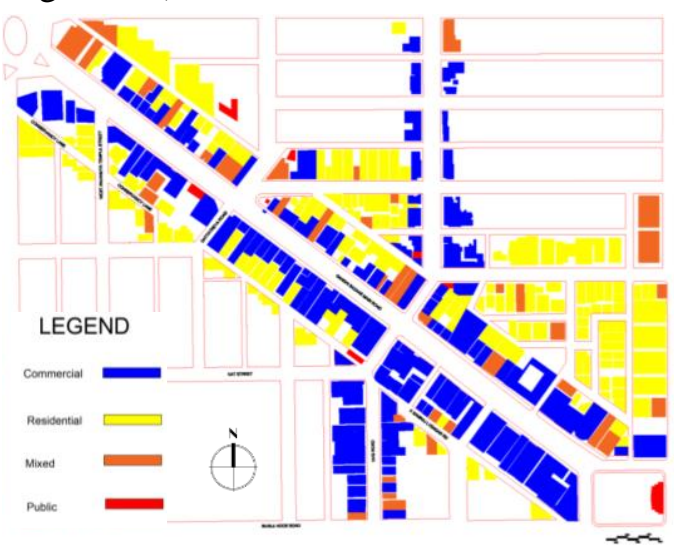

Fig. 5. Land use map of Gandhi Bazaar (Source: Authors) 


\subsubsection{Development Regulation Measure}

When compared to building use recommended by the Bangalore Development Authority, it can be seen that the plots abutting the street were allocated for commercial use but in reality due the economic forces and demand, lot of the residential use has been converted to commercial. This phenomenon has resulted in considerable increase in land value. The map (Refer Fig.7) shows the buildings which violate the development control regulations.

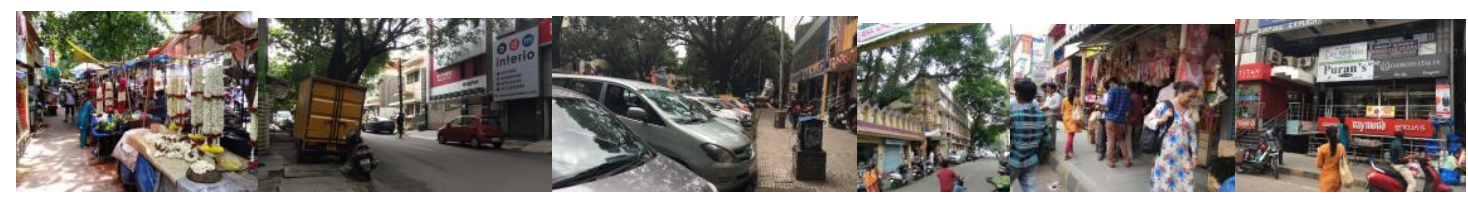

Fig. 6.Series of pictures showing reduced width of footpaths (Source: Authors)

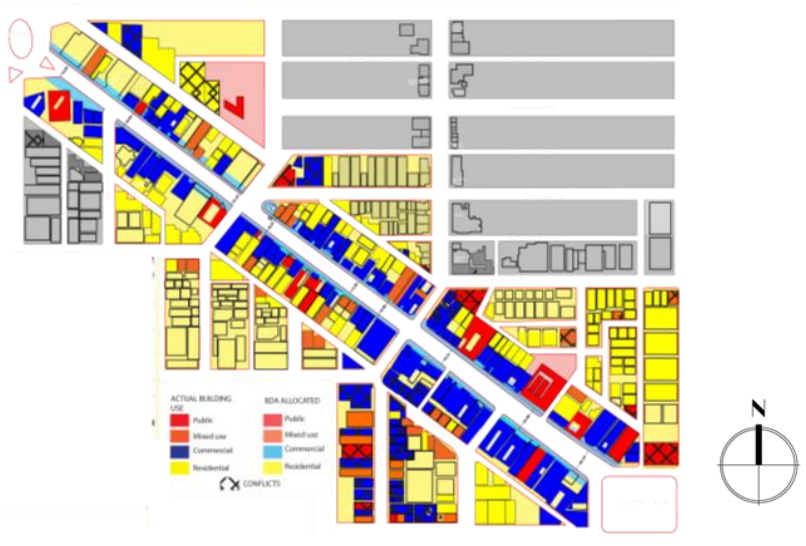

Fig. 7.Map showing extent of violation of development regulations (Source: BDA and edited by authors)

\subsubsection{Physical and social infrastructure}

- $\quad$ Street - Traffic and Circulation

Street pattern and typologies of it forms the main guiding template in shaping the physical layout of an area or neighborhood having major impact on the accessibility criteria. Denser street networks increase connectivity and offer vibrant negotiations on everyday base. Urban morphology reveals the hierarchical pattern of the street network.

Basavanagudi Extension Plan, 1894 (Refer Fig.2) specifically indicates the prominence given to pedestrians through its street hierarchy to promote walkability of the neighborhood. Earlier streets had 8.0M wide footpaths (Refer Fig.8) which now range between1.15M to 3.9M (most of these shrunk footpaths are occupied by vendors and parked vehicles) owing to uncontrolled growth and increased vehicle density (Refer Fig.6). 


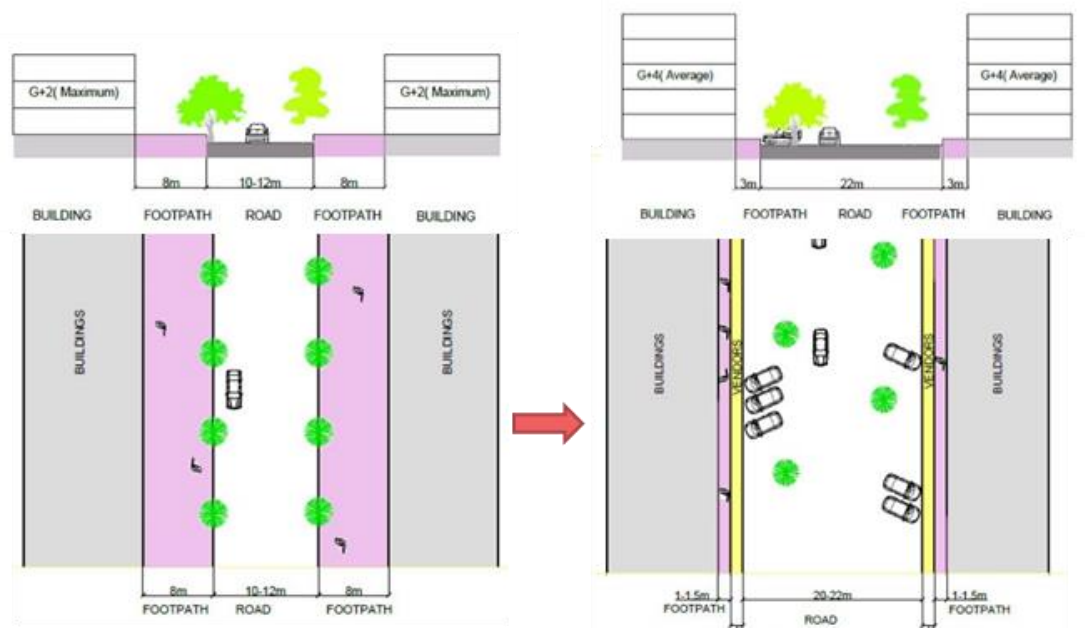

Fig. 8.Reduced width of footpaths (Source: Authors)

The area is well connected by different street hierarchies and public transportation facilities within walkable distances (Refer Fig.9 \&10 respectively). The bus route is unidirectional along the Gandhi bazaar main road from Tagore circle to Ramakrishna ashram circle. The metro is also in the close proximity to the market, making it convenient for people of Bangalore to commute to the area. Gandhi bazaar being the famous historic destination for several activities, attracts of traffic both masses and vehicular. The encroachment by the vendors makes it difficult for the pedestrians to walk on footpath. The pavements are narrow and not maintained properly. On - street unauthorized parking leads to the traffic jams and makes walking for pedestrians difficult especially during peak hours and festival days. The area needs better pedestrian infrastructure and streetscape facilities to augment the active transport (walkability and cycling) which is widely contemplated as one of the major decisive factor in enhancing public health and better quality of urban environment.

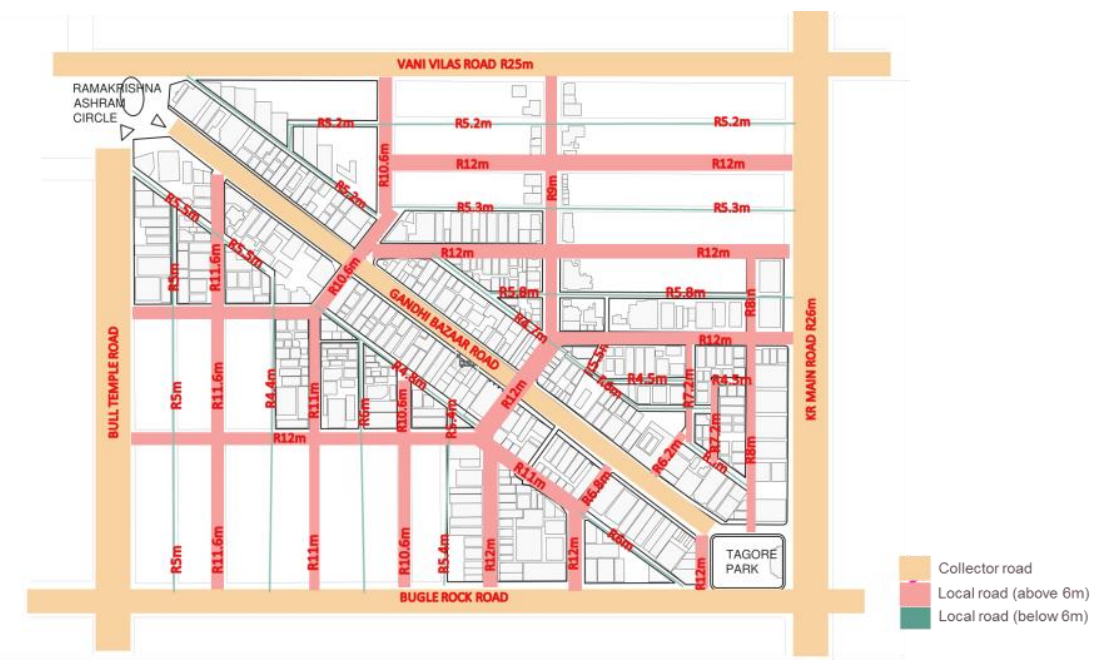

Fig. 9.Map showing different road hierarchies (Source: Authors) 


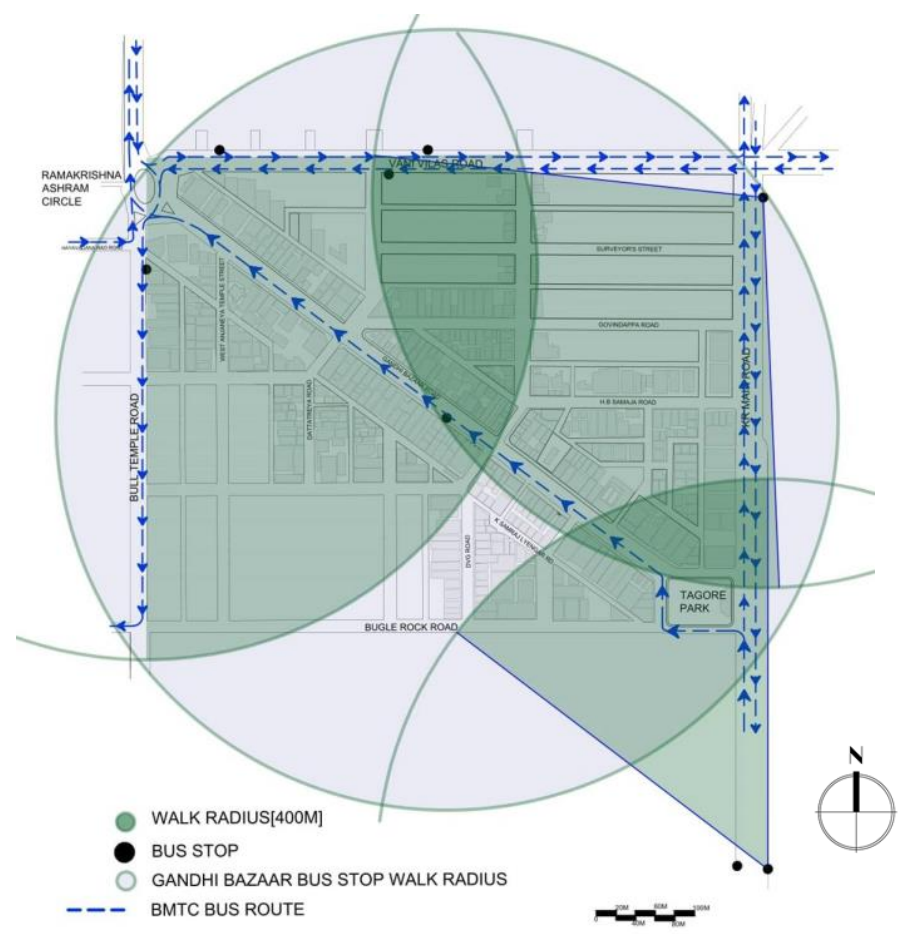

Fig. 10.Map showing major traffic movement along with bus stop locations and walkability radius (Source: Authors)

- Social Infrastructure

A city's human resource is actively productive when it has wider and inclusive accessibility to adequate social infrastructure in turn fostering equitable economic growth. The neighbourhood is well connected with all the social amenities such as schools, health care, post office, police station, fire station etc. (refer Fig. 11).

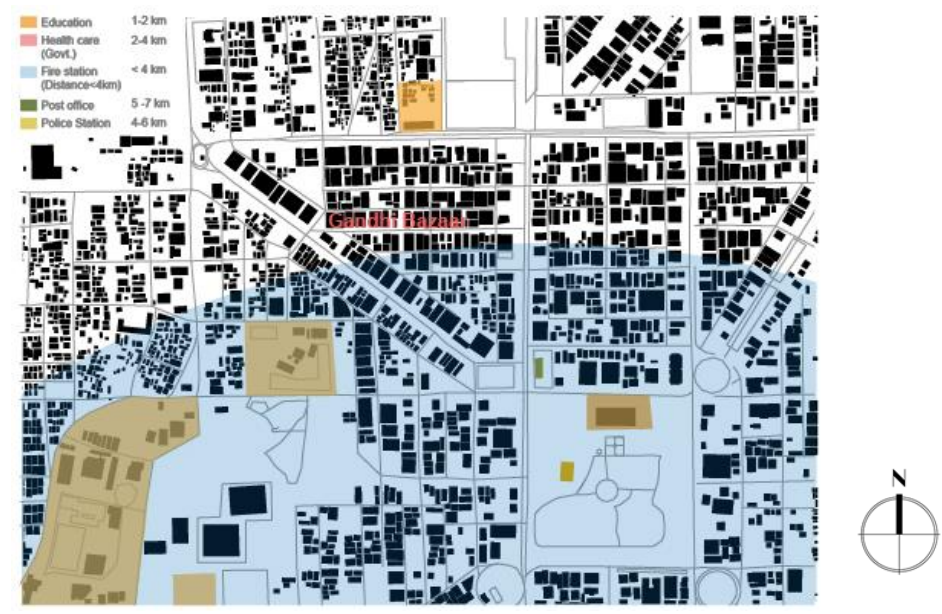

Fig. 11.Map showing social amenities in the precinct (Source: Authors) 
- Fire safety

The conservancy lanes parallel to the main Gandhi bazaar street have a right of way of $5.20 \mathrm{M}$, whereas per National Building Code the minimum with of any street for the ease of fire tender movement should be $6.0 \mathrm{M}$. Fire station is located $4 \mathrm{~km}$ always from the area with given traffic fire tender will take at least twelve minutes to reach the destination. Assuming that all the structures are made of RCC and the rate of spread of fire is $1.15 \mathrm{M} / \mathrm{min}$. the map (Refer Fig.12) was prepared keeping in mind the evacuation window. From the map it can be summed up that there will be quiet damage in case of fire. It was observed that in most of the cases, material used by vendors/Hawkers for hawking is fire prone. This particular aspect is being aggravated by the absence of strict enforcement of development rules.

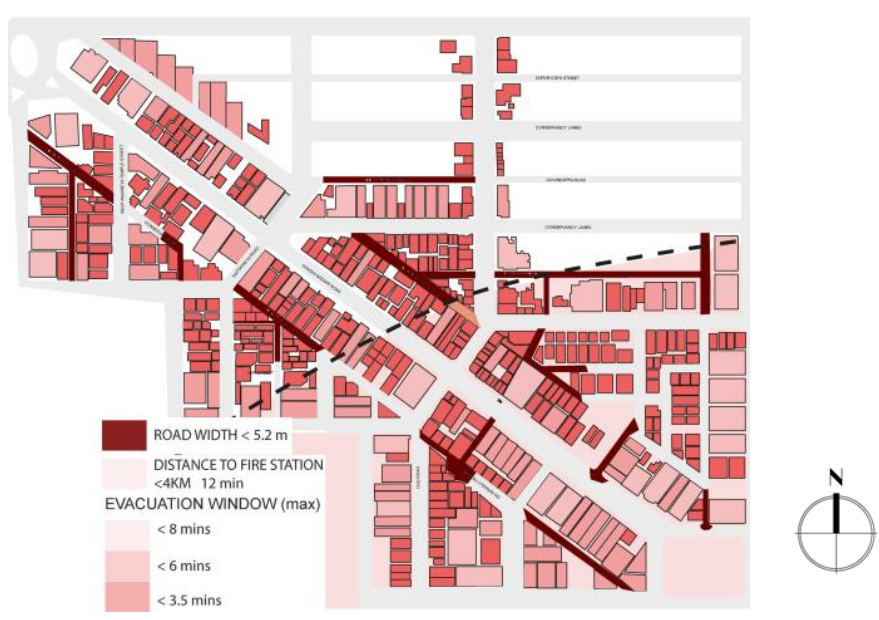

Fig. 12. Map showing evacuation window in case of fire (Source: Authors)

\subsubsection{Built form Environment}

- Building Height

Building heights directly corresponds to the density of the locality and the supporting utility infrastructure. The study shows that approximately $30 \%$ of the area is dominantly structures are four floors high. The numbers of these structures are almost the same comprising about approximately $27 \%$ of the total built form. The number of single floor structures are the approximately 20\% (Refer Fig. 13). Over, the period of time the scale of the precinct has transformed from single floor structures to four and more storeys structures (Refer Fig. 14). 


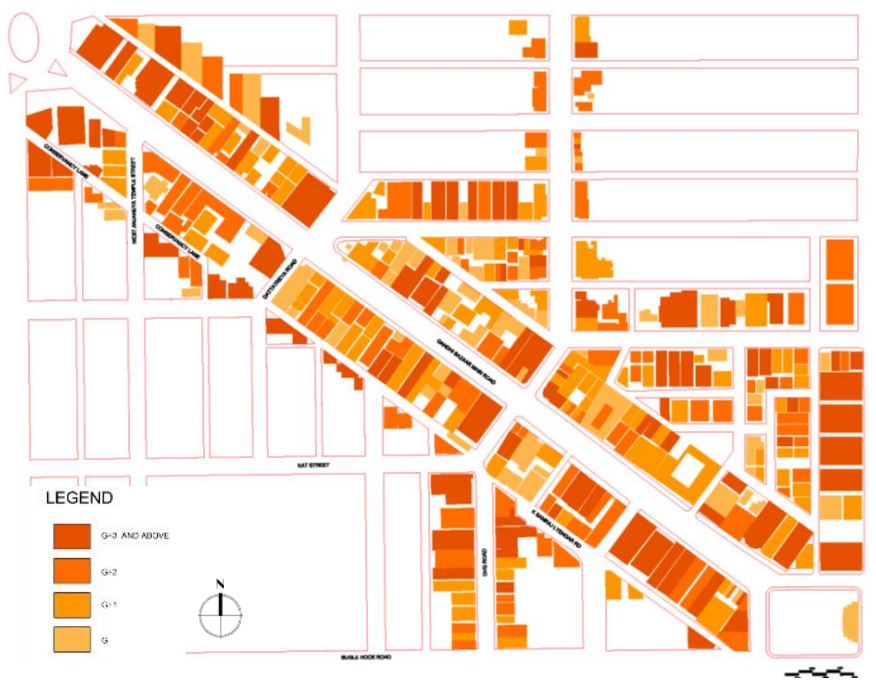

Fig. 13. Building Height map of the study area (Source: Authors)

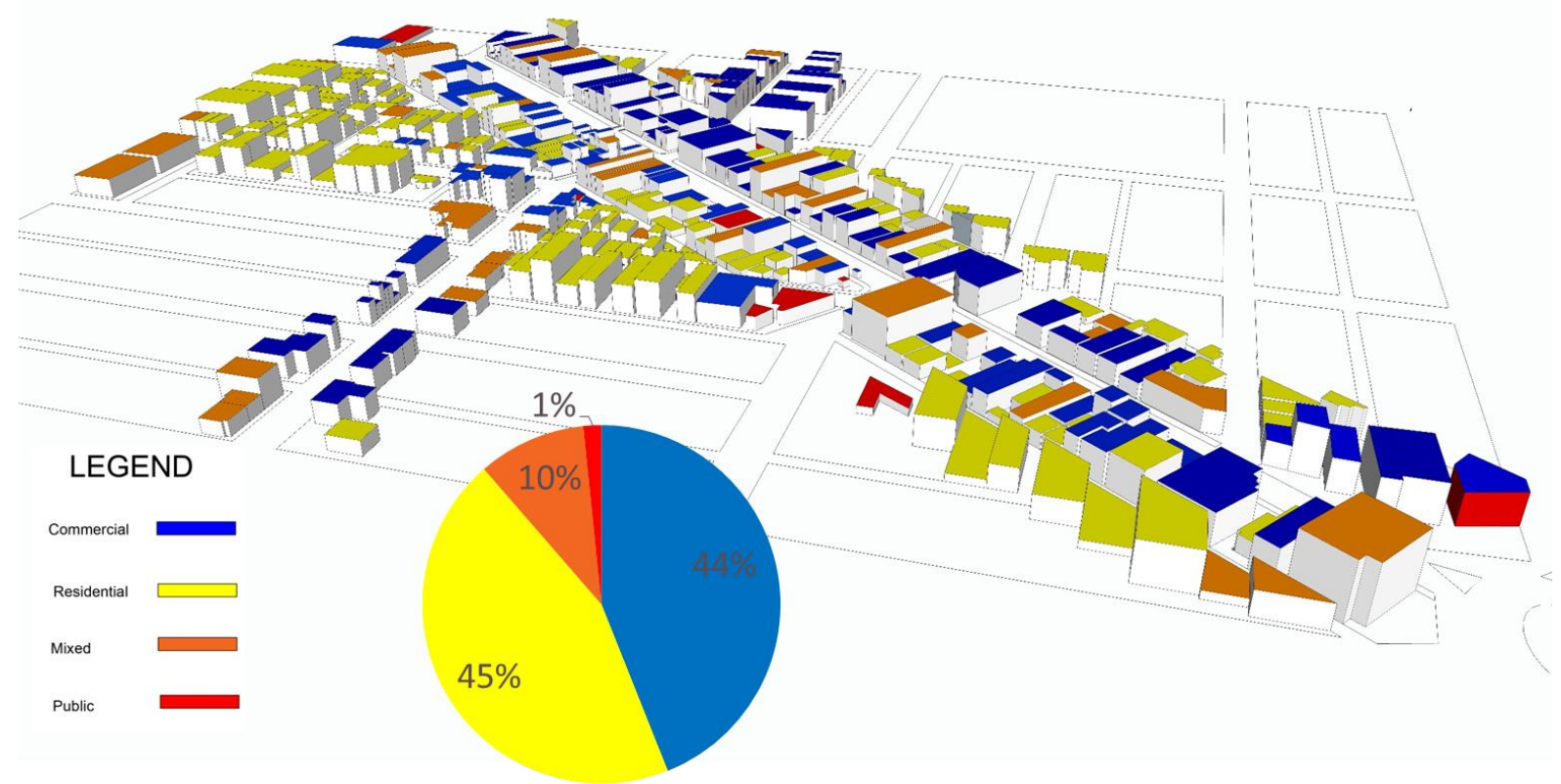

Fig. 14.Percentage composition of building heights along with their uses (Source: Authors)

Under the pressure of increased demand for real estate, old buildings have been either demolished or revamped to suit contemporary necessities (Refer Fig. 15). 

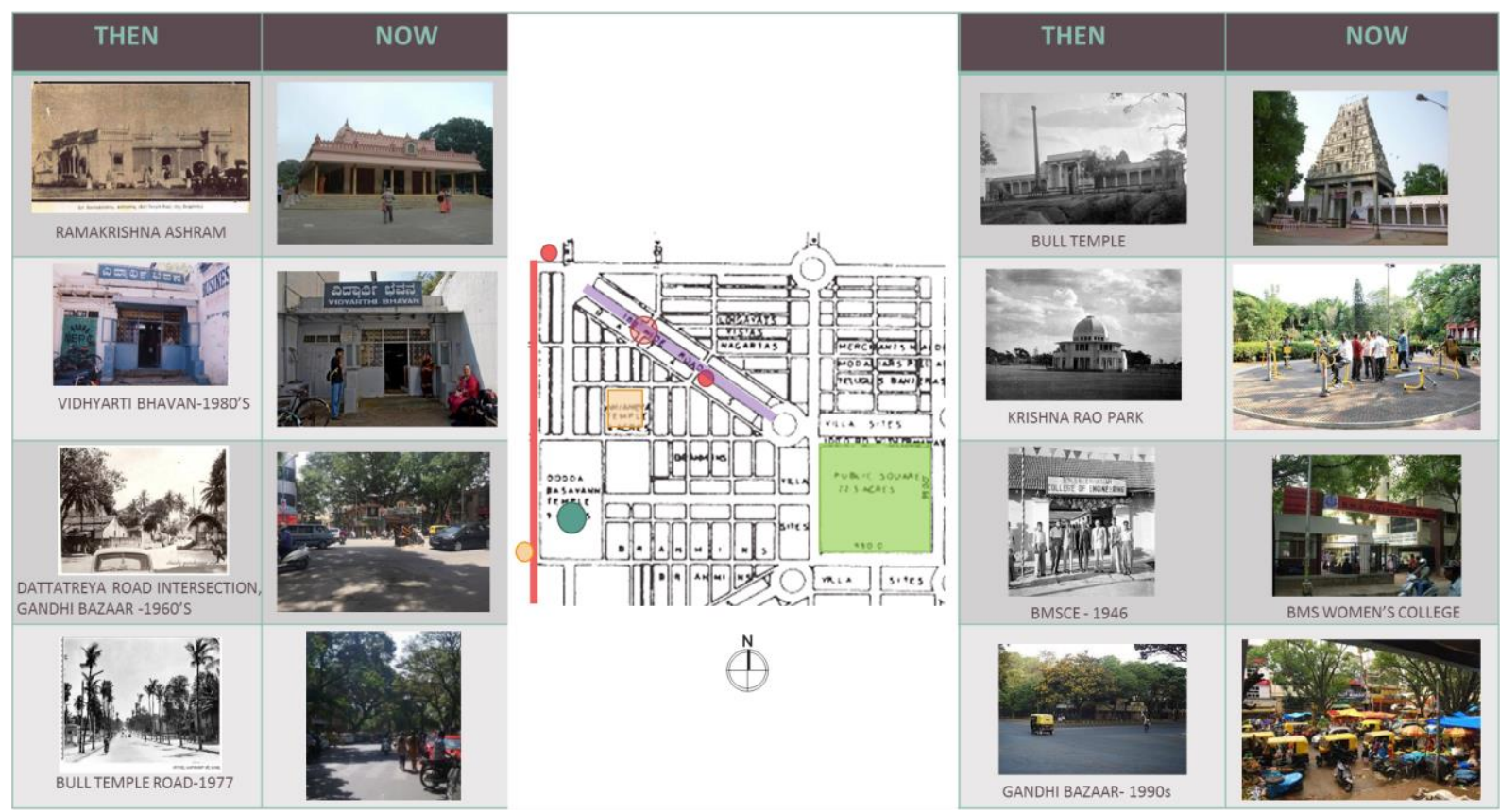

Fig. 15.Transformation of built forms to suit contemporary necessities

- Built to Void Relationship

A figure ground diagram allows for clear articulation of urban spaces and the connecting elements to link these spaces. The prime location of land has led to mixed used development of larger foot prints transforming the urban grain from cohesive fine grain (which responds to human scale) to coarse. The buildings are increasingly getting denser over the years due to the strategic location of the area and increase in land value. Figure ground here clearly indicates two distinct typologies of urban void: streets as linear grids and large open spaces as the temple premises, playgrounds and parks (Refer Fig. 16).

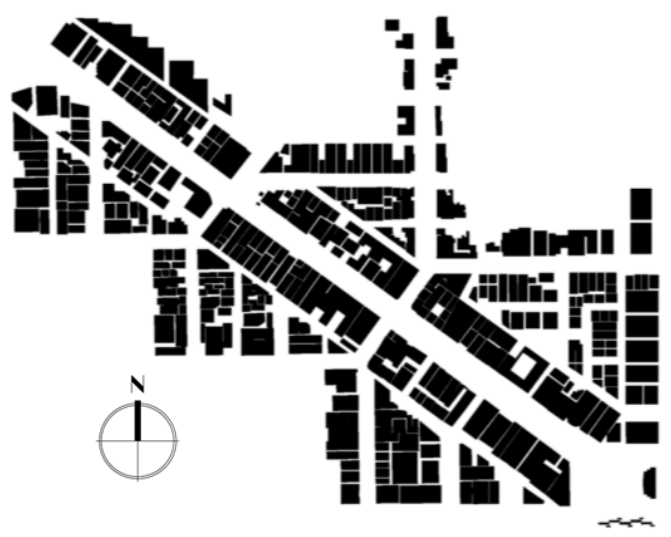

Fig. 16.Map showing built to void map (Source: Authors) 


\section{- Building Age}

The area being one of the early planned extensions has several buildings which are more than sixtyfive years old structures (Refer Fig. 17). Flower market building is one of the oldest structures still currently in use in the area. The building is in dilapidated condition and needs immediate restoration. The structural stability and energy consumption audit should be done in order to mitigate the consequences of disaster. Detailed morphological information of the building stock and ccontinuous monitoring and assessment fosters the planning of long term strategies.

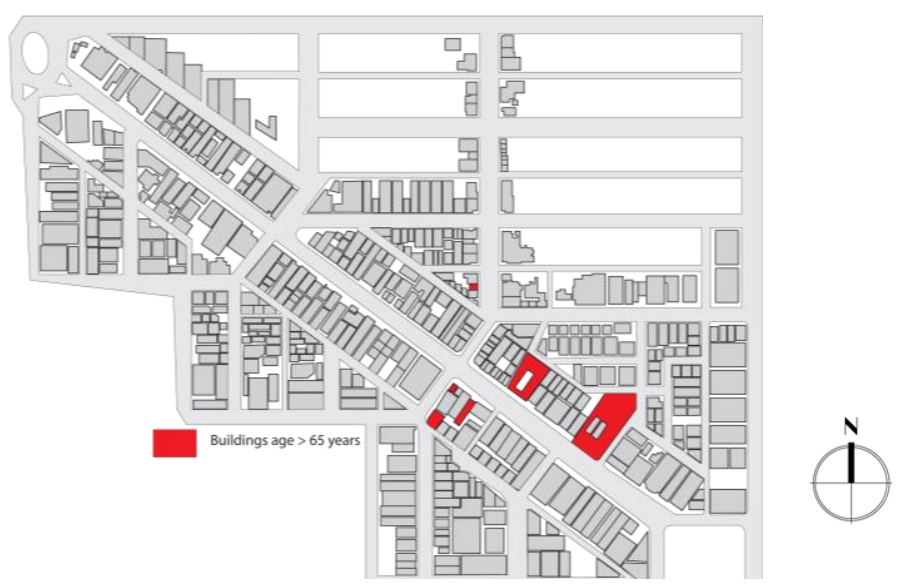

Fig. 17.Map showing the dilapidated buildings.(Source: Authors)

\subsubsection{Public Realm}

Public realm, essentially representing the integral part of shared community space influences form and function of the neighborhoods. The current development of built environment is excluding the user group there by creating inappropriate and meaningless spaces. Thousands of people traverse through the area on daily basis for diverse activities (Refer Fig.18).

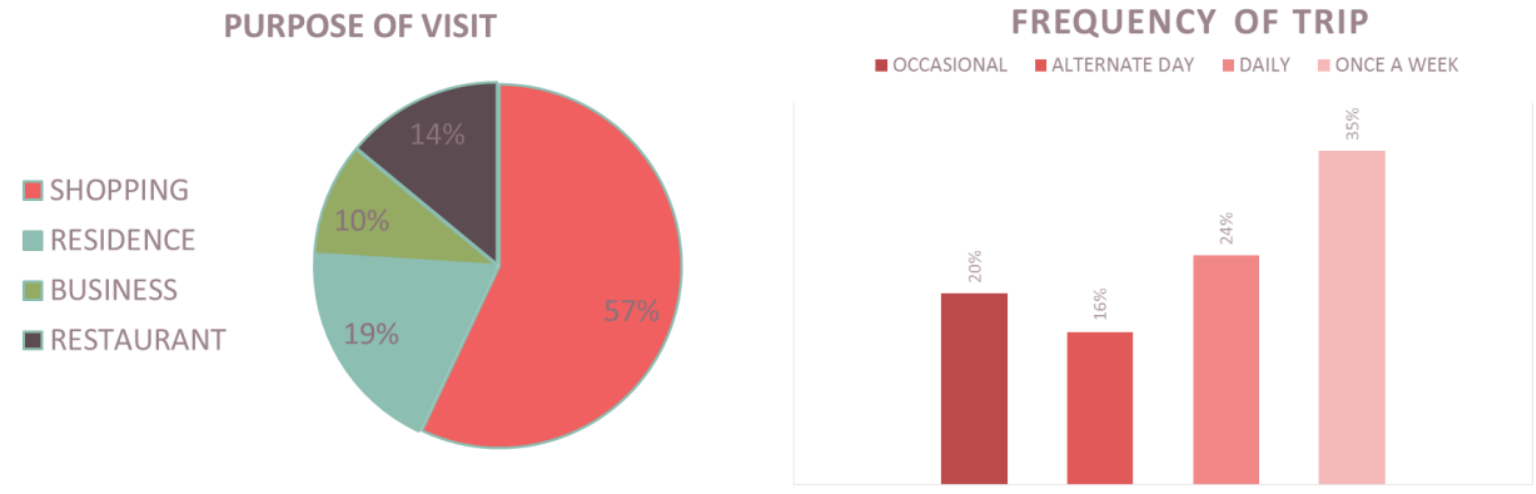

Fig. 18.Purpose and frequency of people (Source: Authors)

The assorted and active environment of the area provides comfort to the pedestrians on any day. The neighborhood and especially the Gandhi Bazaar street is largely seen as a place of transition 
rather than a place to pause or to be as it majorly lacks well-articulated spaces for social interactions (Refer Fig.19).

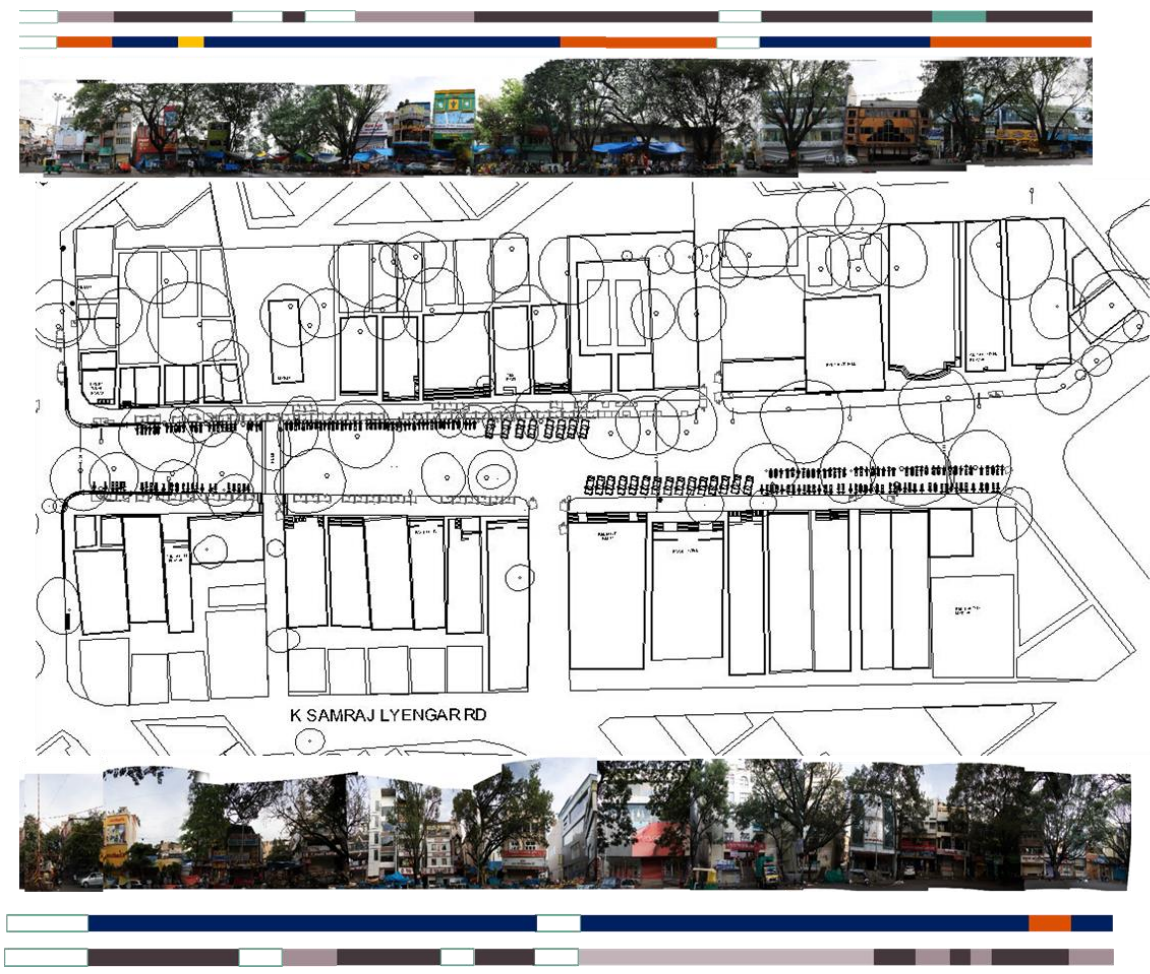

\section{Building Use:}

Commercial

Public / Semi Public

Residential

Mixed Use

Plinth Level

Step Up, Step Down

Step Up, Ramp Down

No Entry Point

Fig. 19.Non-cohesive streetscape (Source: Authors)

The area with its vibrancy renders one with sensorial experience and exploration. The area's wide network of streets, public spaces and parks/open spaces is not being potentially used to create safe environments (Refer Fig.20, 21, 22 \& 23).

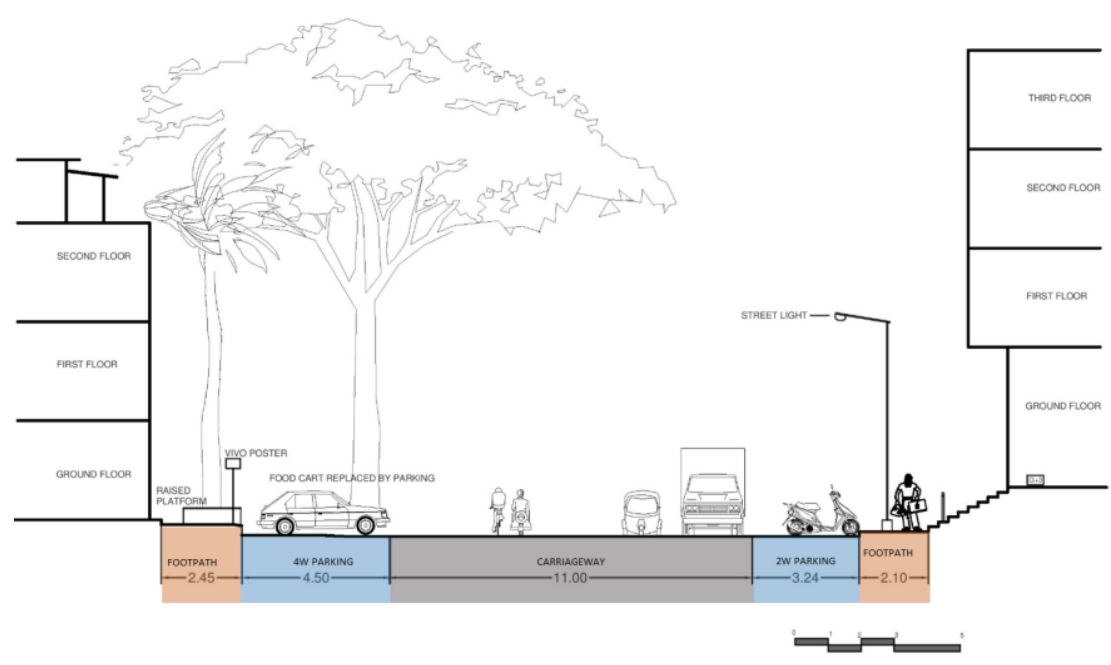

Fig. 20.Edge condition - commercial uses on either side (Source: Authors) 
7th International Conference on Research in Science and Technology October $19-21,2018$

Munich - Germany

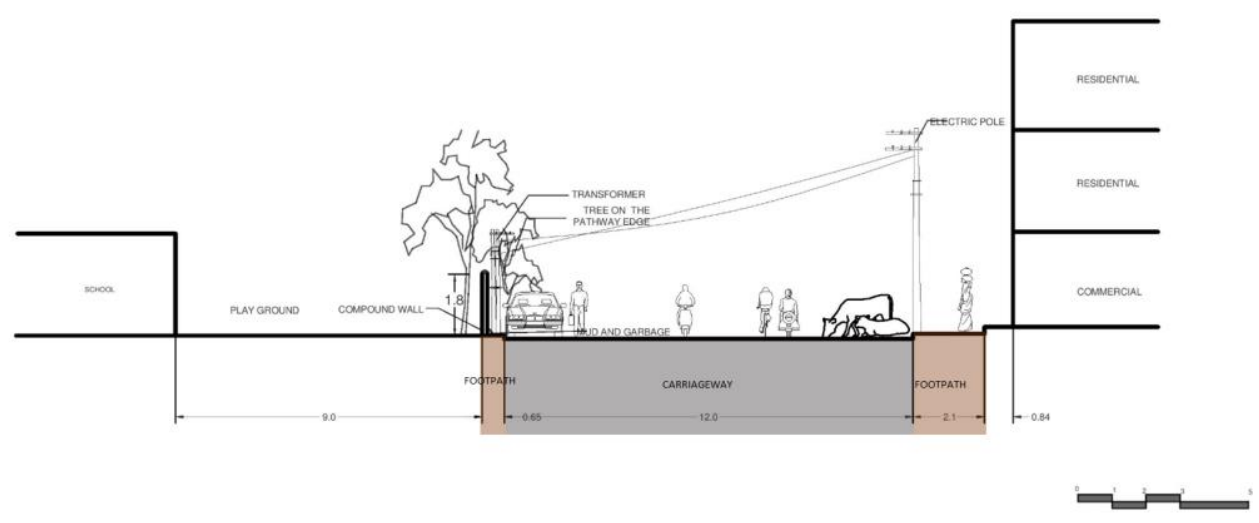

Fig. 21. Edge condition - mixed uses on either side (Source: Authors)

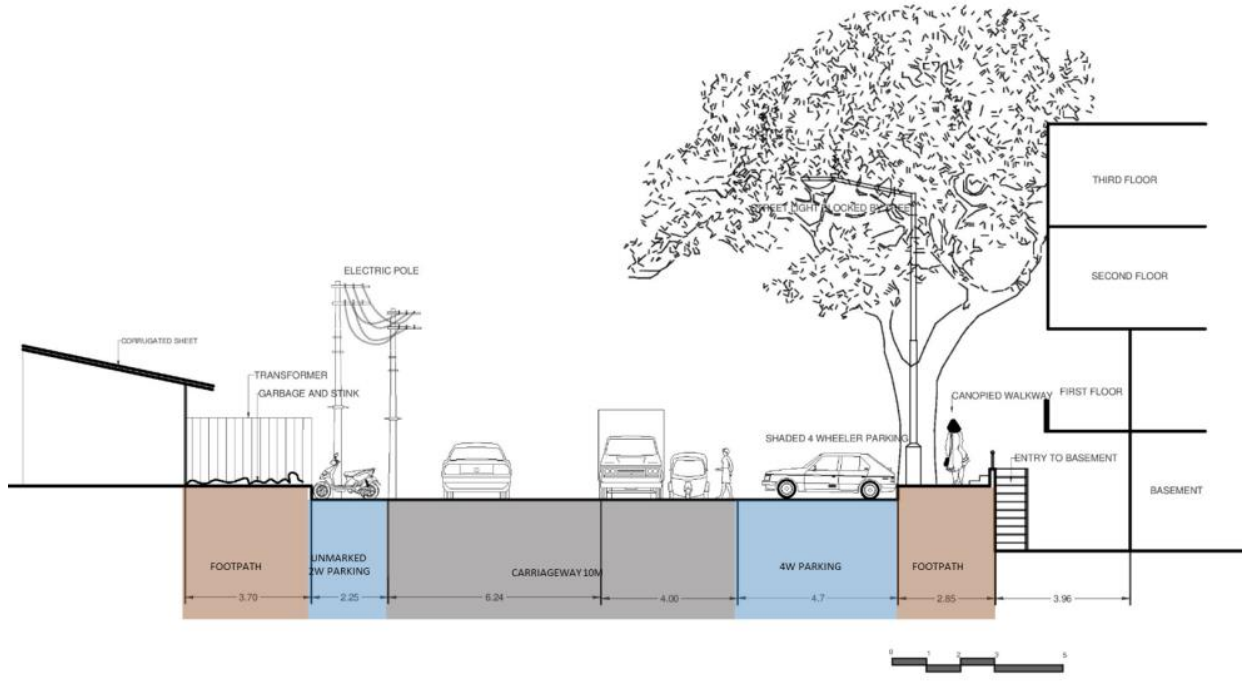

Fig. 22. Edge condition - commercial and utility networks on either side (Source: Authors)

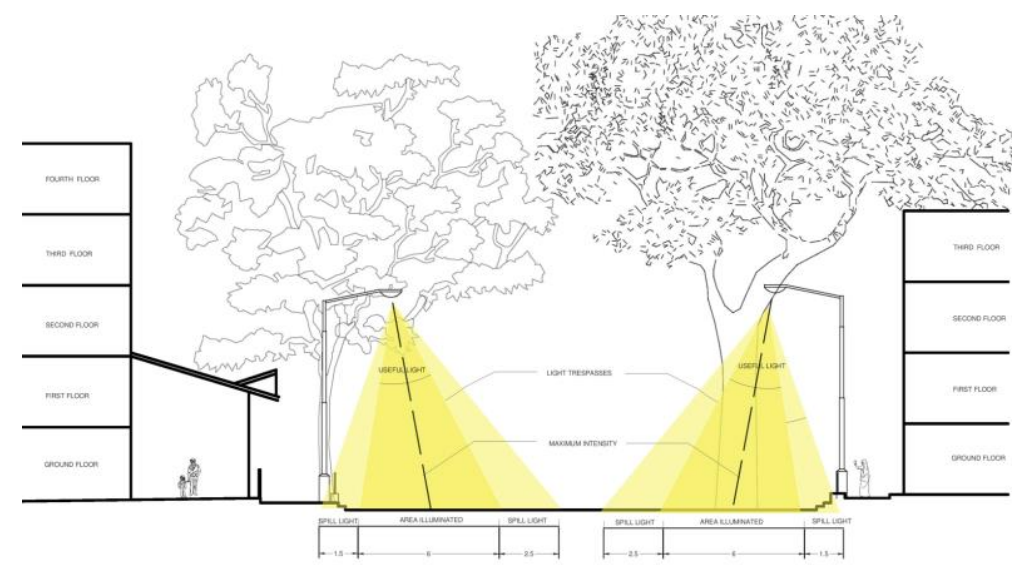

Fig. 23. Poor qualtiy of street lighting focussed only on ROW (Source: Authors) 
- Building Façade :Imageability and accessibility

The process of building the imageability of an environment is undoubtedly the result of an interaction between the observer and the environment influencing mutually. Continuity is essential in creating imageability and experience. Comprehendible and interrelated built environments foster imageability of a space. The building facades are disordered and discontinuous as they lack any type of architectural language. The survey conducted revealed that on goers find only $17 \%$ building as attractive and almost $41 \%$ buildings as unattractive (Refer Fig.24, 25 \& 26).

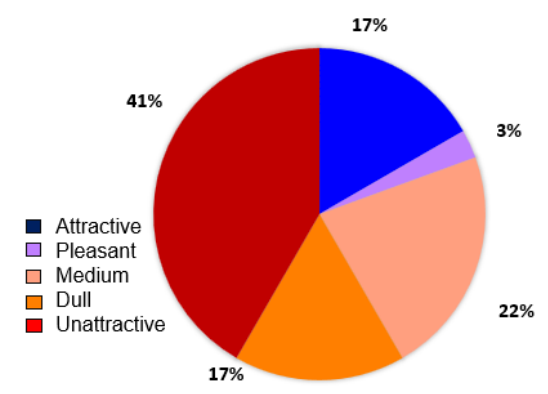

Fig. 24. On goers perspective on façade quality of buildings. (Source: Authors)

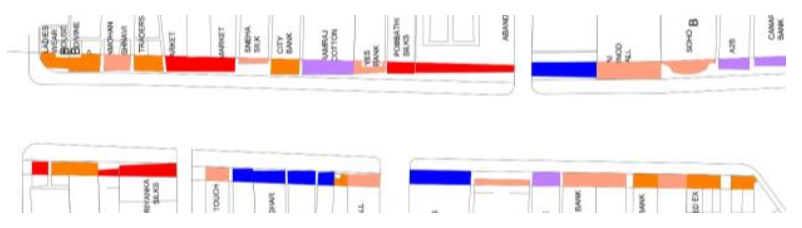

Fig. 25. Map showing on goers perspective on quality of façade (Source: Authors)

Visual clues always do not communicate the fine difference between public and private which are either generally or selectively accessible (Refer Fig.26).

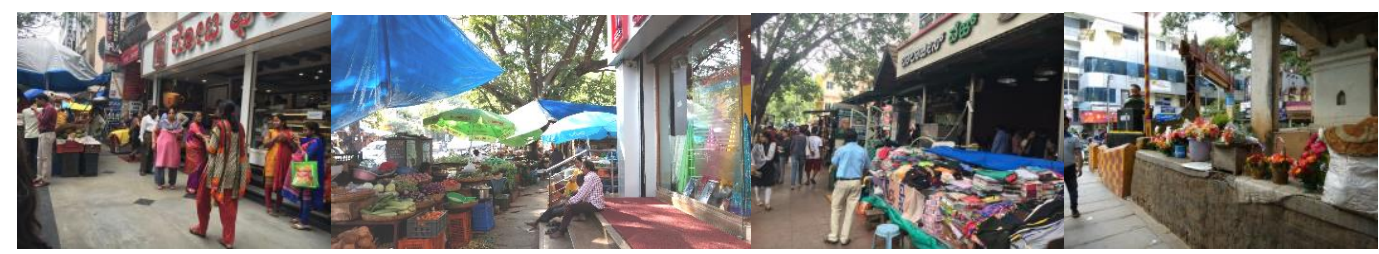

Fig. 26. Images showing lack of communication between public \& private (Source: Authors)

- Active Transport- Walking and Cycling

Apart from health benefits (such as exposure to natural space, improved physical activity and psychological health, enhancing creativity), usage of active transport provides a numerous of benefits. Walking and cycling allows in forming a place- based connection with the background, context and community of the neighborhood and city. Furthermore, engaging in active transport facilitates social interaction strengthening a sense of place and belongingness. The footpaths in the area are always encroached by vendors and the situation turns more chaotic during festivities as 
well as social occasions (Refer Fig. 27). Huge piles of unsegregated solid waste generated are dumped on the sidewalks further adding to the distresses of pedestrians and cyclists (Refer Fig. 28).
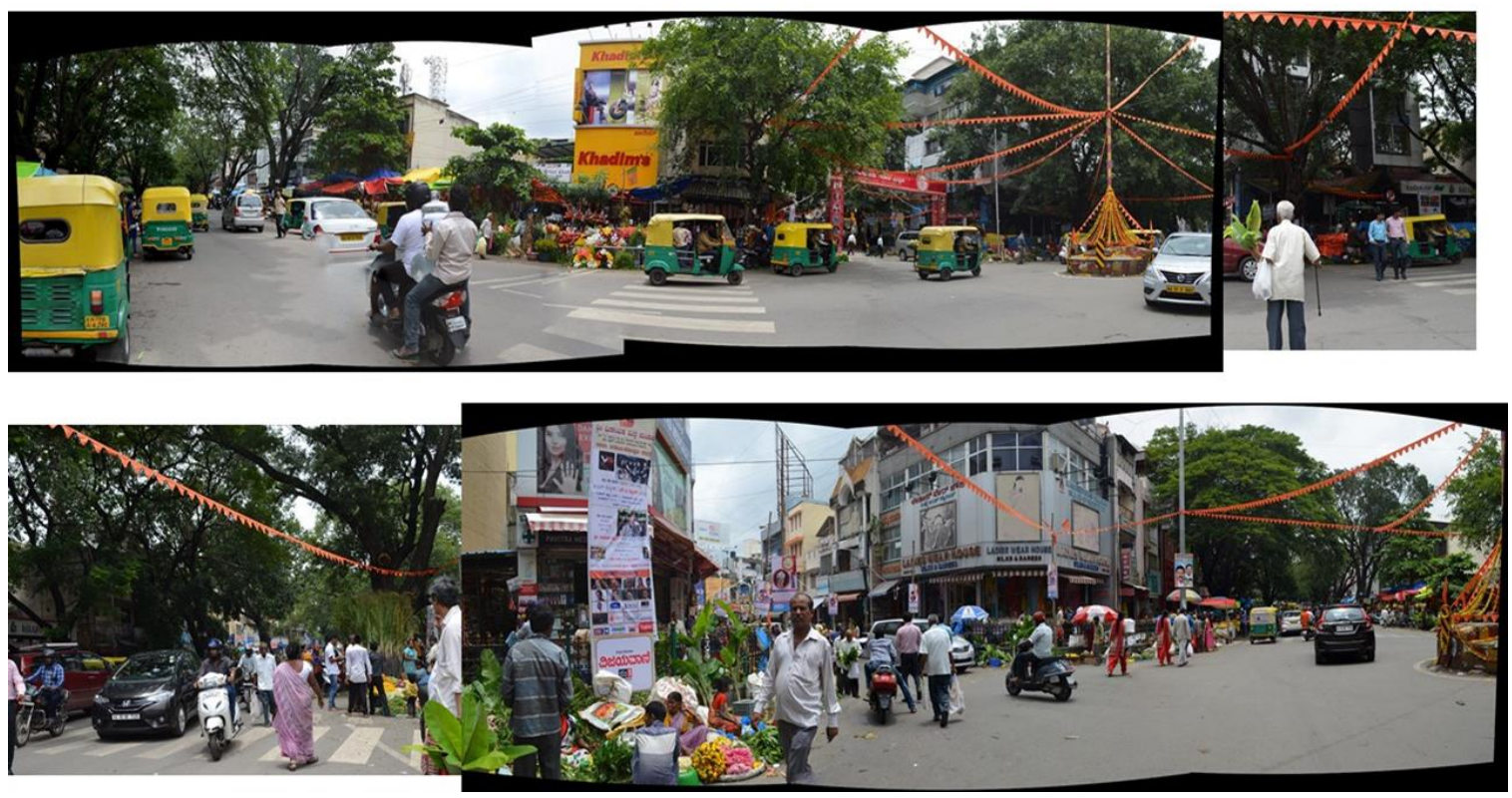

Fig. 27. Images showing encroached footpaths (Source: Authors)

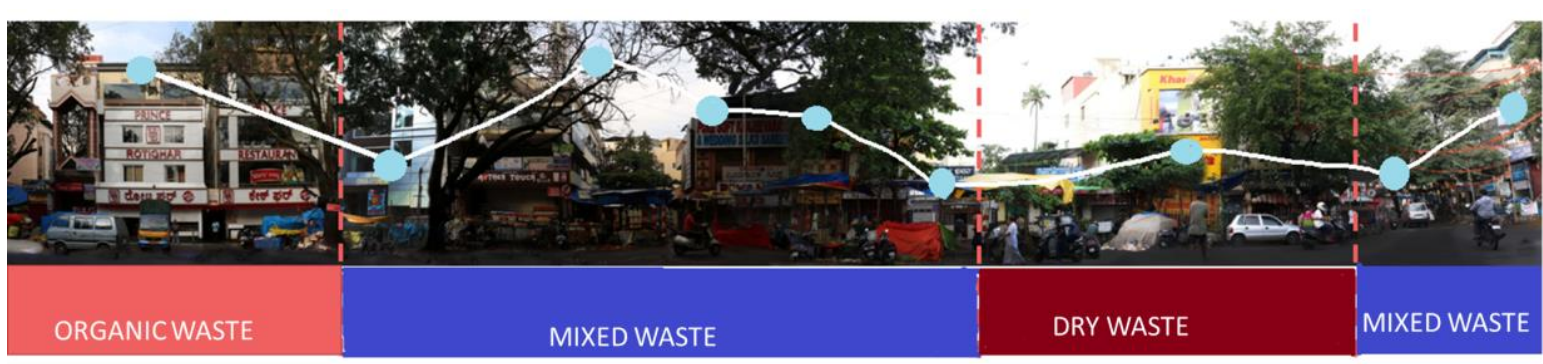

Fig. 28. Analysis of different types of waste generators (Source: Authors)

The positive and transparent facades will portray more sense of welcoming which will create communication between the people and the place. An analysis of form and function through use, access and perception is appropriate to plan and design livable environments that are appreciated by the communities. It can improve the imageability of the neighborhood while safeguarding property values and creating conducive atmosphere.

\subsubsection{Green/ Open Spaces}

Urban open and green spaces include open spaces, sports fields, edges of roadway/railway/waterways, parks, botanical gardens, patches of vegetation, etc. The study area along with linear greenway (series of trees) has two famous neighborhood parks. Mahogany, Rain tree and Gulmohar trees are prominent trees along with few other native species. The wide spread of canopy and green spaces of the area are home to local flora and fauna (Refer Fig. 29). 


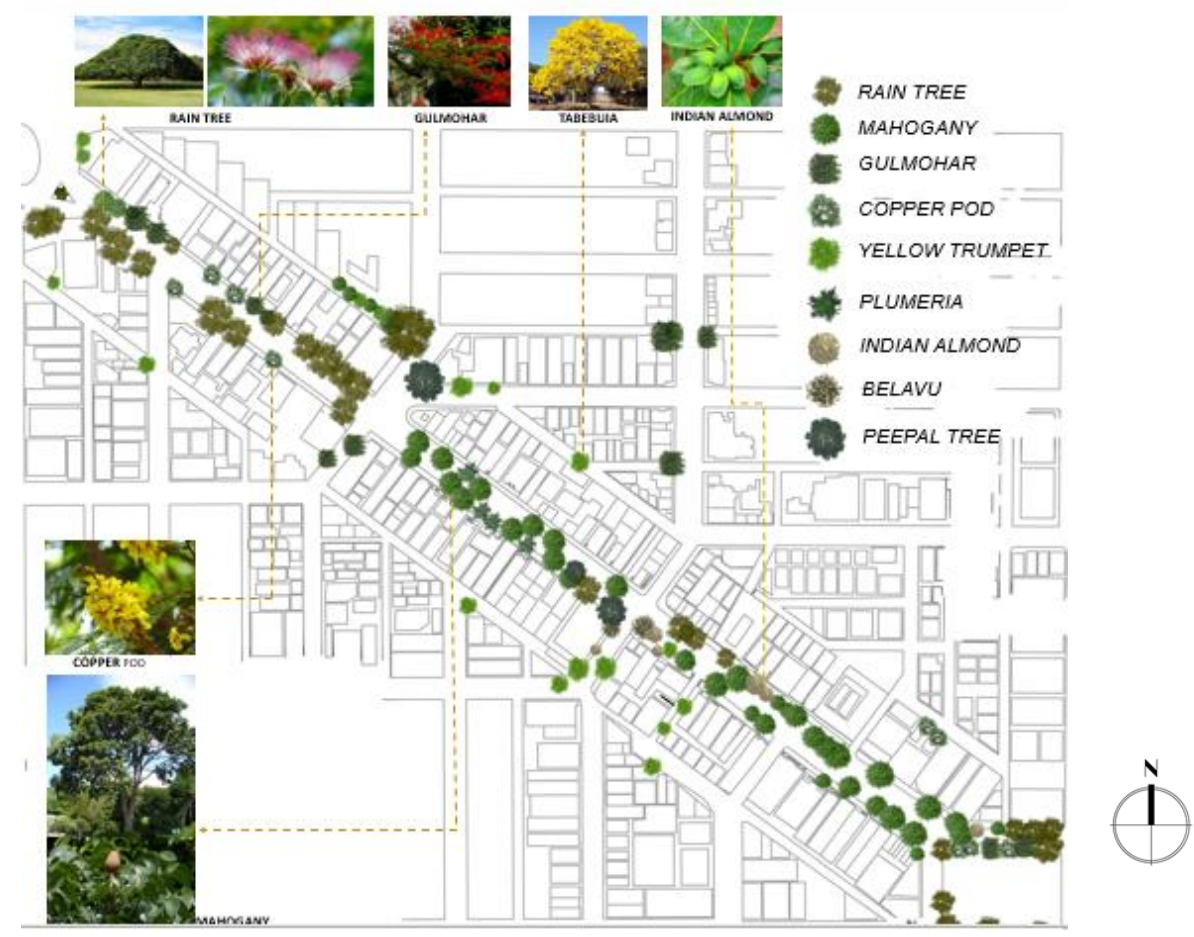

Fig. 29. Map showing d types and location of trees (Source: Authors)

Trees besides providing shade and comfort to passer-by, are interactive urban nodes. Not only trees are used by vendors in many ways to display their products also, but also by people who congregate under shade to socialize (Refer Fig.30). These spaces need to be inter-connected and maintained to enhance the user experiences in turn retaining the green cover.

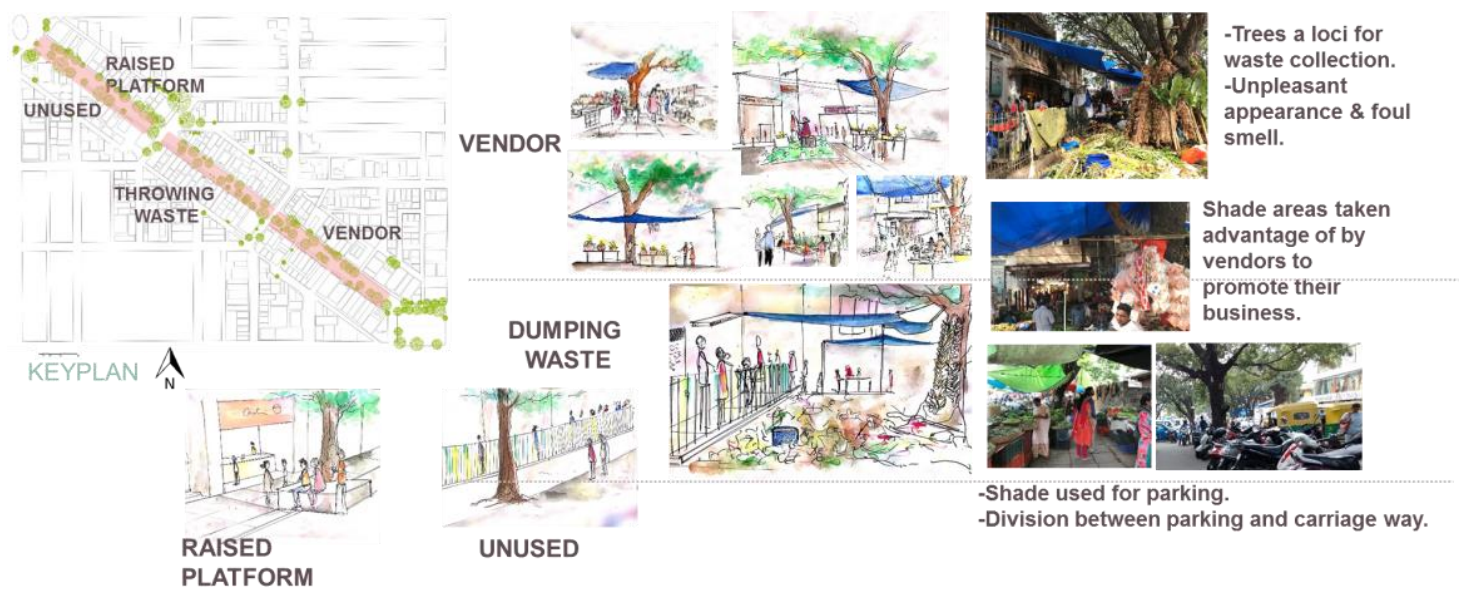

Fig. 30. Trees as activity nodes (Source: Authors)

\subsubsection{Users Profile- Inhabitants and vendors}

Density, connectivity and fine grained land use diversity factors strongly influence the diverse user group. The density of users in an urban area is the result of the conditions of the built environment. 
7th International Conference on Research in Science and Technology

October $19-21,2018$

Munich - Germany

The temporal distribution and patterns of the number of user group are closely linked to the dynamism of the area and may enhance the experiential quality by providing increased chances of interaction (direct and indirect) with other people and activities. The study area is frequented by diverse users for generic and specific purposes (Refer Fig. 31) and temporal variations do occur at different periods of time (Refer Fig. $32 \& 33$ ).

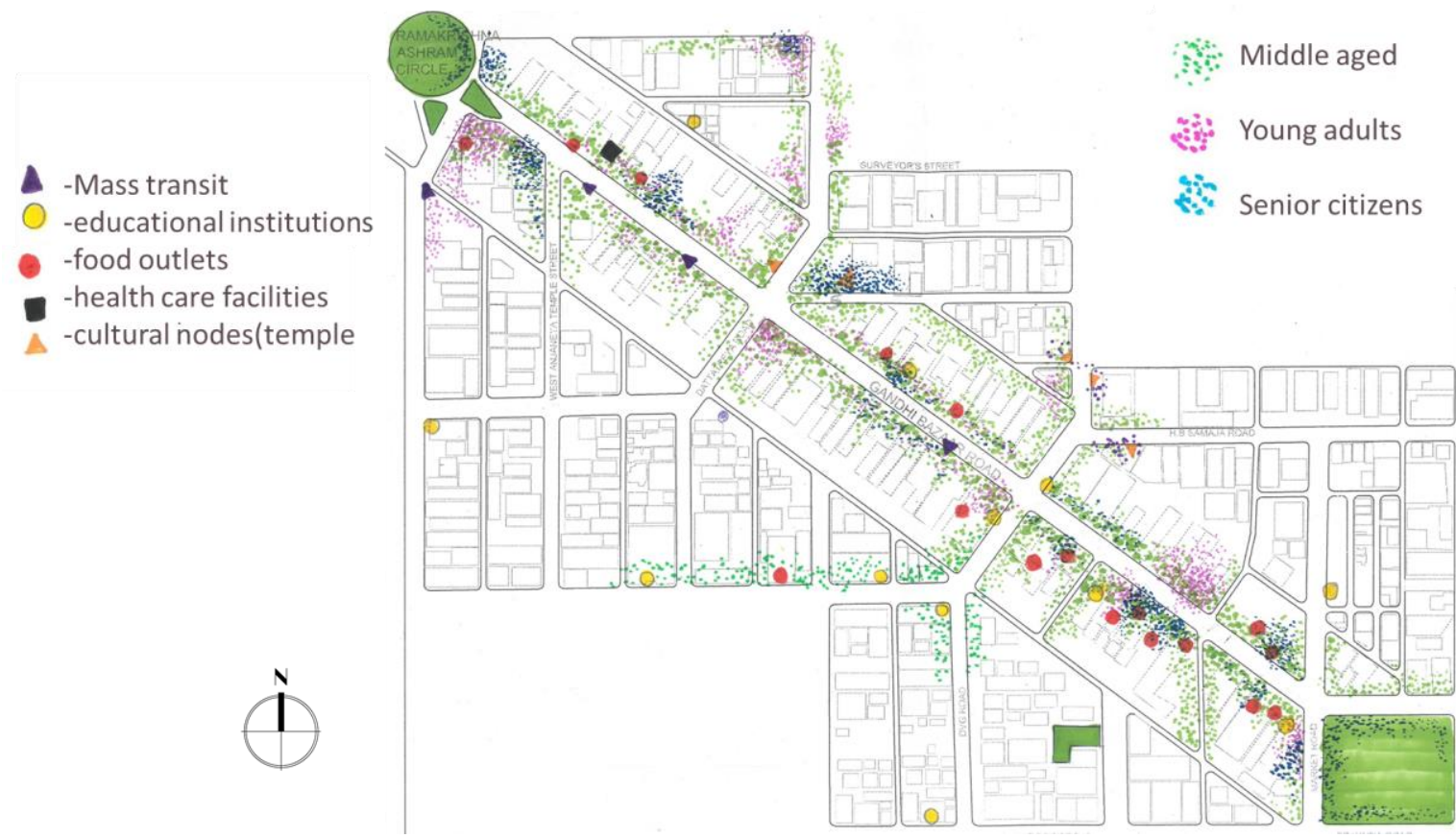

Fig. 31. Frequented locations of users (Source: Authors)

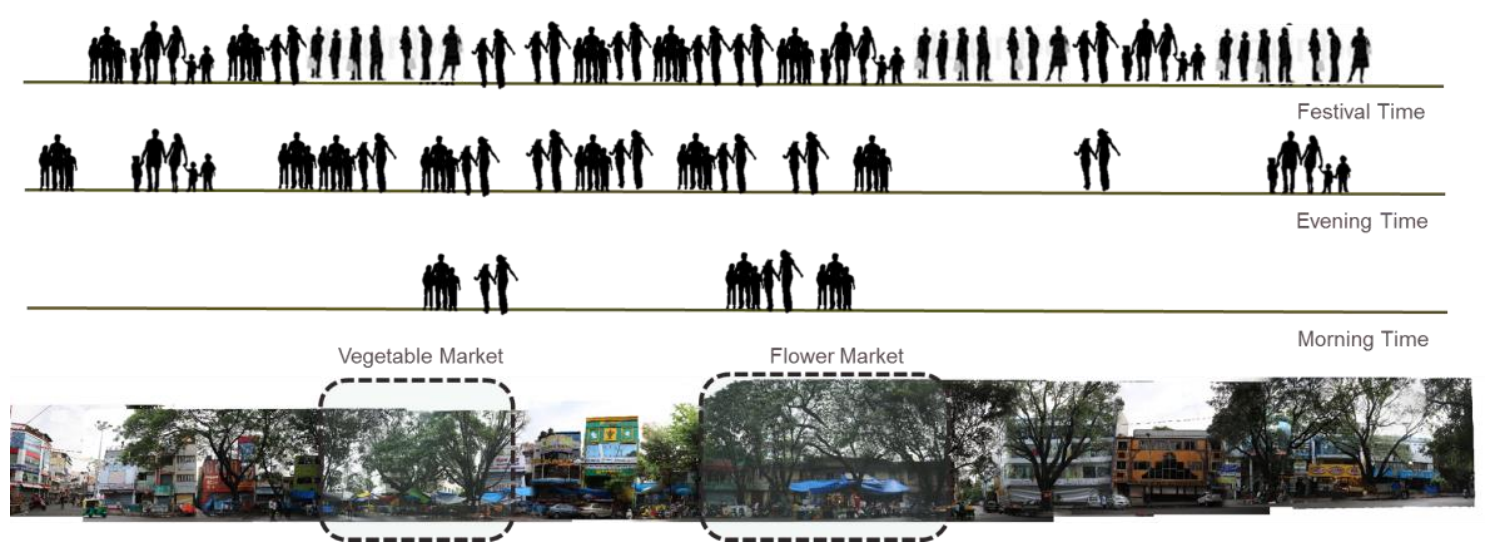

Fig. 32. User density profile (Source: Authors) 

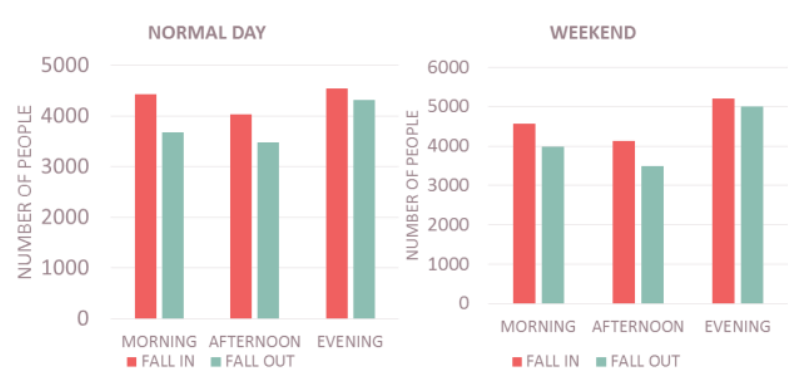

Fig. 33. User density profile - Temporal variations (Source: Authors)

With increasing urban migration and the shrinking formal sector, hawking and street vending have emerged as one of the critical means of earning a livelihood for the urban poor in India. Street vending is an important activity related to informal sector in urban areas. As long as our urban roads are used by the various cross sections of inhabitants, street vendors will remain inevitable. Street vendors are the broadly defined as persons who offer goods and services for sale to the public without having a permanent built-up structure but with a temporary static structure or mobile stall with various area requirements (Refer Fig.34).

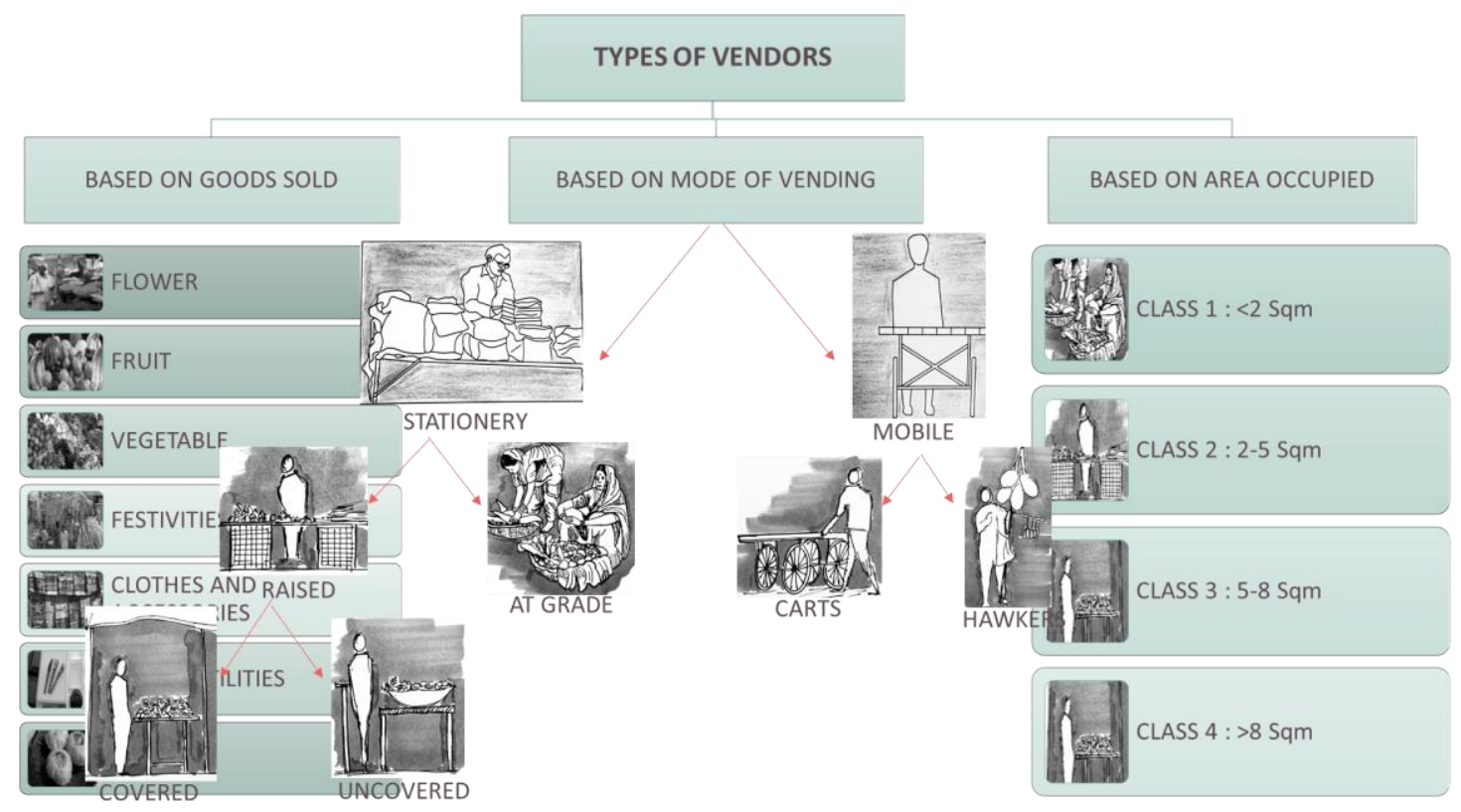

Fig. 34. Vendor typologies (Source: Authors)

Bicycles, pedestrians and bus traffic attract street vendors, often selling stuff which are in demand by road users. Vendors often locate themselves at places which are natural markets for them. A careful analysis of the location of vendors, their numbers at each location and the type of services provided clearly shows that they are needed since they work under completely 'free market' principles. If their services were not required at those locations, they would have no incentive to be there. (Refer Fig. 35, 36, 37, 38 \& 39). 
7th International Conference on Research in Science and Technology October $19-21,2018$

Munich - Germany
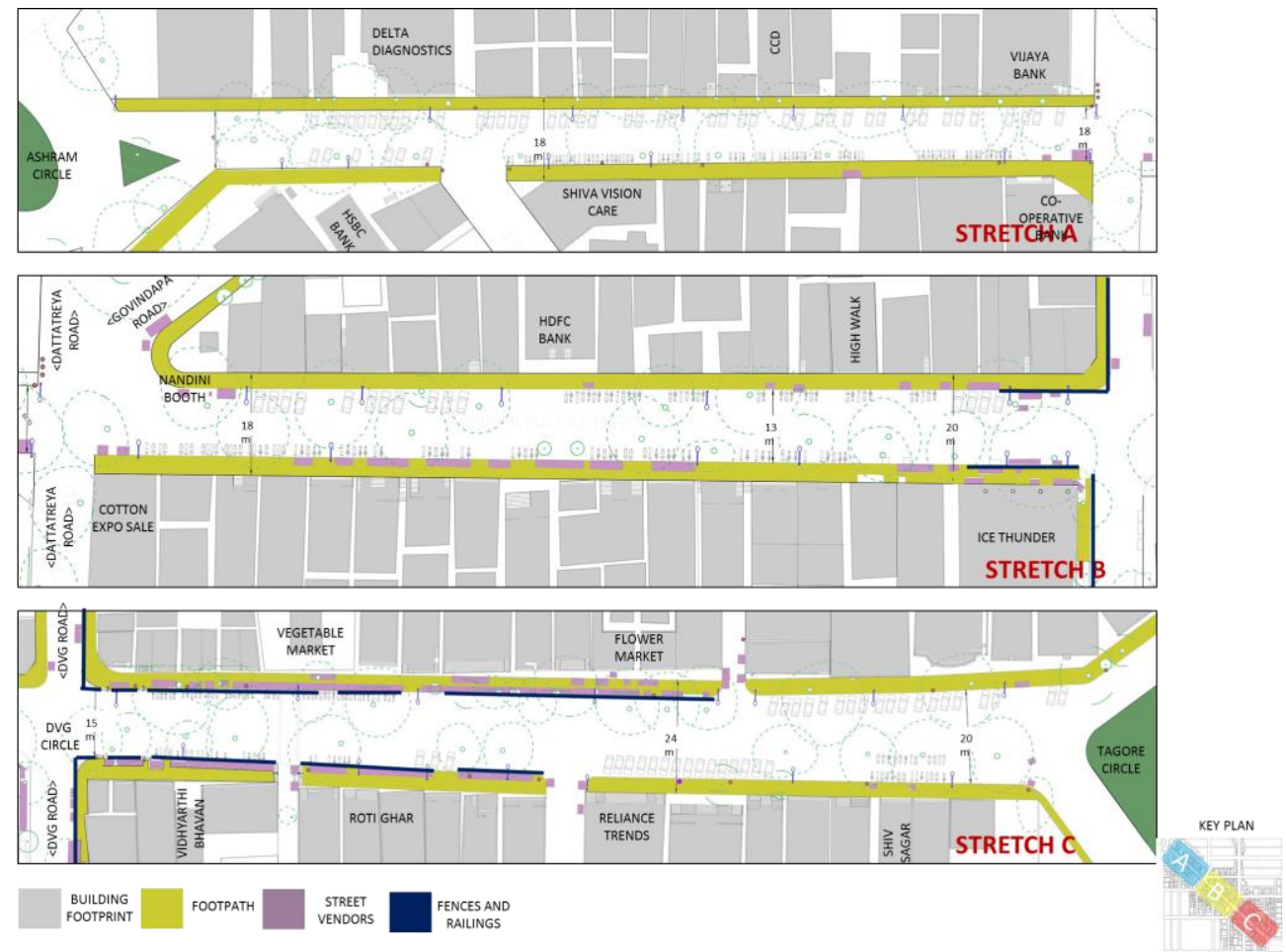

Fig. 35. Mapping the locations of vendors (Source:Authors)

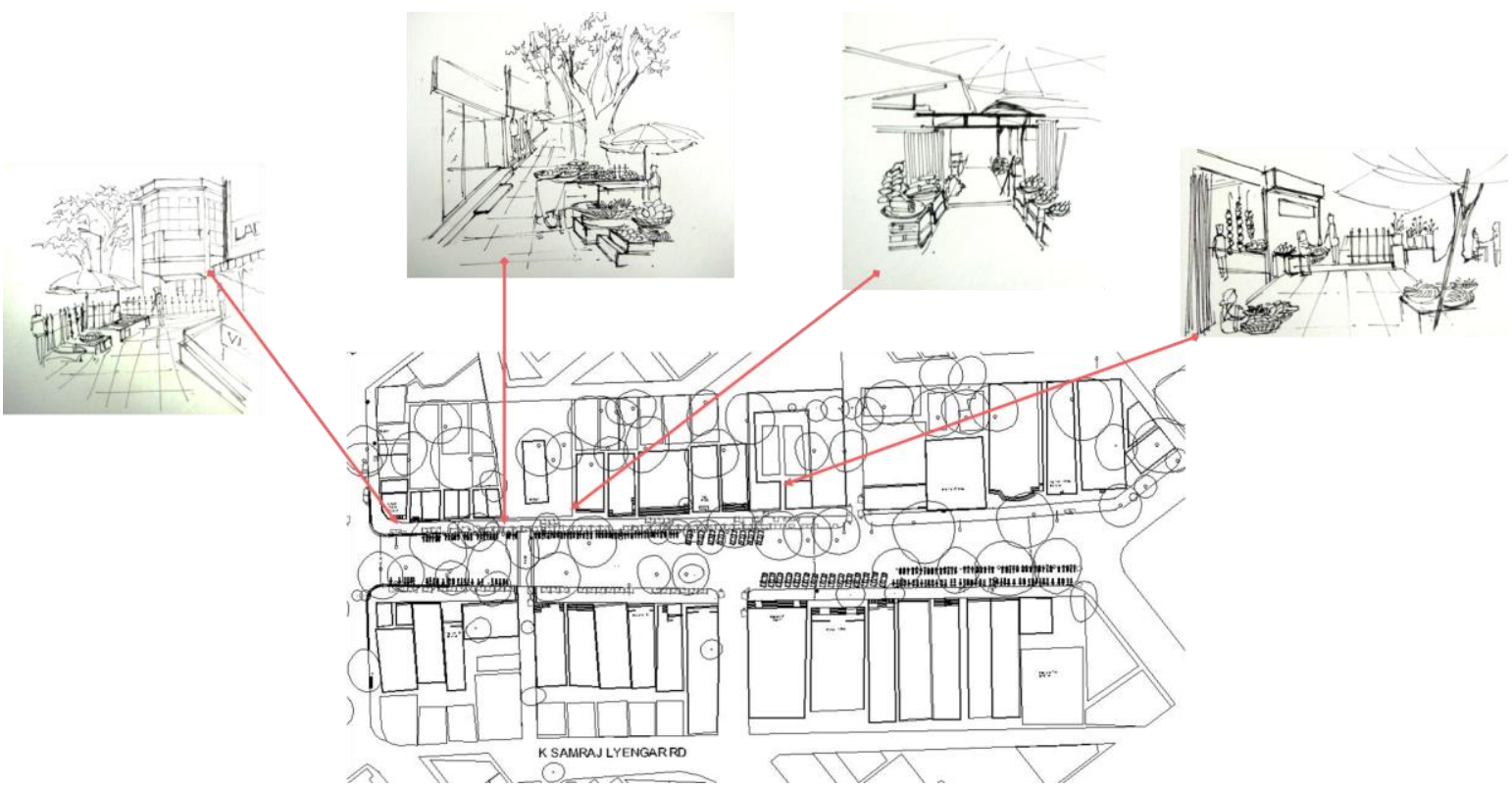

Fig. 36. Location of vendors and typologies (Source: Authors) (Source: Authors) 


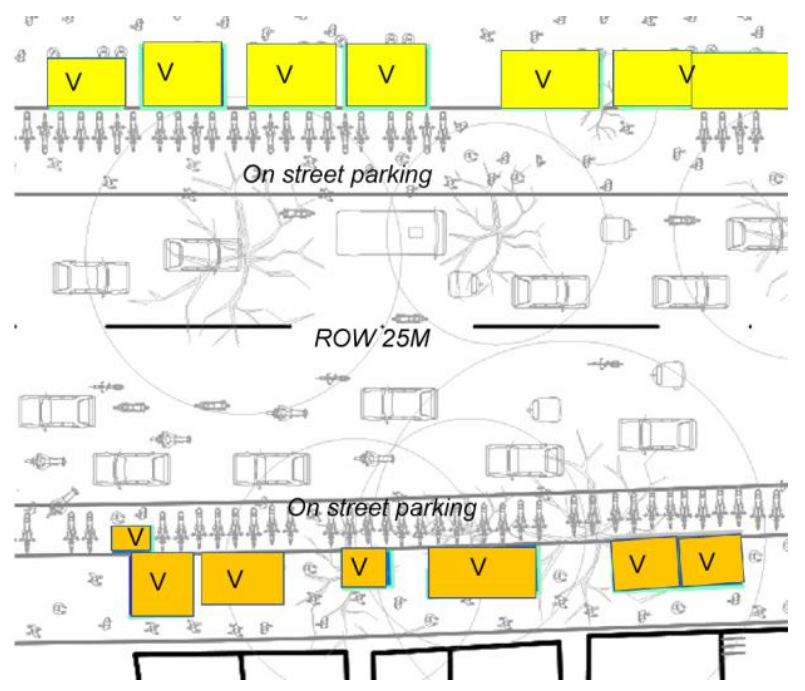

Fig. 37 Part plan showing vending activities on footpath (Source: Authors)

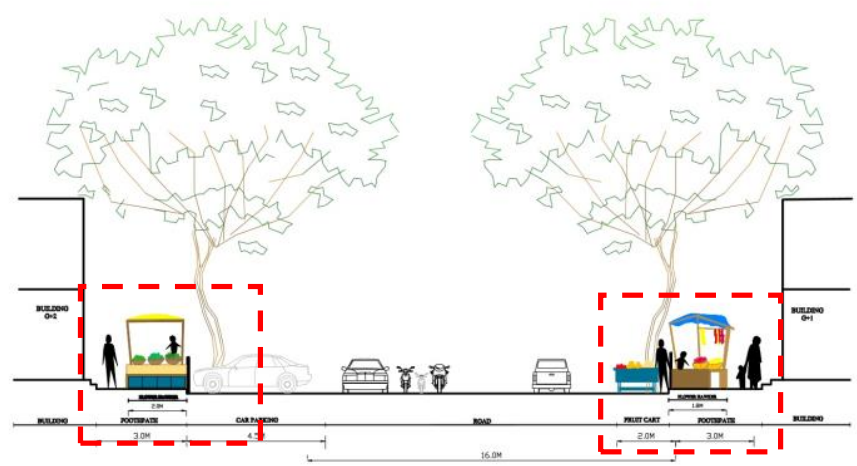

Fig. 38 Section highlighting vending activities on footpath (Source: Authors)

The spatial arrangement of vending activities is organic and temporal in nature. The arbitrator location of the vendors leads to encroachment of pedestrian space on the footpath. Street vending provides many opportunities: goods and services at convenient locations, and affordable prices; self-employment for large numbers of people; links formal sector with consumers; keeps streets busy and safe, creates an interesting city environment.

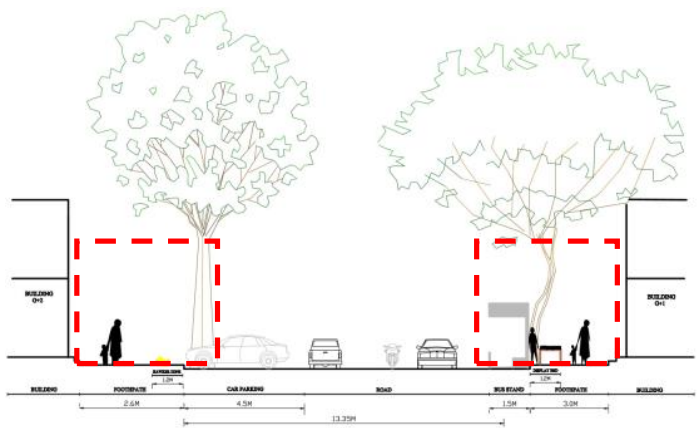

Fig. 39 Section showing vending activities on footpath (Source: Authors) 
A comprehensive planning policy, design scheme and implementation mechanism needs to be evolved to integrate street vendors into urban form (Refer Table 1).

Table 1. Comprehensive planning policy, design scheme and implementation mechanism (Source: Authors)

\begin{tabular}{|c|c|c|}
\hline Description & $\begin{array}{l}\text { Implementing } \\
\text { Board / Committee }\end{array}$ & Funding \& Regulatory framework \\
\hline $\begin{array}{l}\text { a) Spatial management of vending areas } \\
\text { through: } \\
\text { - Creating space for vendor zones within } \\
\text { existing infrastructure by efficient design. } \\
\text { - Usage of incidental space to the } \\
\text { advantage. } \\
\text { - Time sharing of space. } \\
\text { b) Provision of proper hawking space to } \\
\text { avoid conflict with customers } \\
\text { c) Integration of hawking units with } \\
\text { organized retail spaces in their present } \\
\text { location itself. } \\
\text { d) The design of the public squares and } \\
\text { spaces can be done in a manner so as to } \\
\text { accommodate the hawkers and the street } \\
\text { vendors in the design itself integrating the } \\
\text { visual context into the image of the urban } \\
\text { fabric. }\end{array}$ & $\begin{array}{l}\text { City level advisory } \\
\text { body should be } \\
\text { formed having } \\
\text { adequate } \\
\text { representation of the } \\
\text { vendors and other } \\
\text { civil society groups. }\end{array}$ & $\begin{array}{l}\text { Issuing License (mentioning space } \\
\text { and time specific) \& photo ID cards } \\
\text { (mentioning activity type, location of } \\
\text { vending space along with bio- data) } \\
\text { against payment of charges to } \\
\text { enhance the revenue of ULBs. A part } \\
\text { of this revenue could be used for } \\
\text { provision of basic infrastructure such } \\
\text { as drinking water, toilets and waste } \\
\text { collection and temporary or } \\
\text { permanent structure for vendors. } \\
\text { Zoning regulations and byelaws } \\
\text { which indicate that a percentage of } \\
\text { the total plot should be left for the use } \\
\text { of vending and other types of } \\
\text { informal sector activity in } \\
\text { commercial areas. }\end{array}$ \\
\hline
\end{tabular}

\section{Discussion and Way Forward}

The study examined physical grain based on different morphological measures. The analysis of the study underlines that the better understandings of urban morphological measures in terms of form and functioning of existing urban fabrics to formulate solutions produces better places and better urbanism while creating structured urban compositions.

The three main identified challenges are:

Two-dimensional land use planning paradigm - The more procedural and conceptual nature of planning proposals and policy apparatus in the context of increased socio-spatial and political complexity has lost the emphasis on the perceived quality of the intermediate scale of urban form.

Absence of socio-spatial perspective-The perceived dislocation from socio-spatial concerns (social equity, environmental balance, diversity, etc.) beyond the enduring economic rationale. 
Colossal compositions - This narrates to contemporary development models of larger floor plates that facilitates economic format of current real estate. These seemingly uniform built forms resulting from the consolidation of fine grained collective forms leads to loss of diversity and coherence of urban fabrics of the neighbourhoods.

Although, morphology aspect involves multi-fold of concerns, the urban form of cities considerably affects the quality of everyday life of urban dwellers. Using multiple morphological measures, the study attempts to demonstrate the feasibility of deriving the quantitative results within a given region. Various results of analysis enable comparative assessment of the distributional patterns of morphological characteristics by indicating the overarching variables (Refer Table 2).

Table 2. Attributes and variables urban morphology (Source: Authors)

\begin{tabular}{|c|l|l|}
\hline \multirow{2}{*}{$\begin{array}{c}\text { Urban } \\
\text { morphology }\end{array}$} & Attributes & $\begin{array}{l}\text { Urban morphological study uses both qualitative and quantitative analyses. } \\
\text { It is an important determinant of the urban pattern, urban form and spatial } \\
\text { components. } \\
\text { It is an important tool to understand physical or built fabric of urban form } \\
\text { and processes and users shaping it. } \\
\text { Explorations and prediction of directions of possible urban changes while } \\
\text { addressing the social forces within. }\end{array}$ \\
\hline $\begin{array}{l}\text { Urban } \\
\text { morphology }\end{array}$ & Variables & $\begin{array}{l}\text { Micro level - Related to plazas, squares encompassing form, function, } \\
\text { pattern, structure, volume urban elements, solid/void, etc. } \\
\text { Meso level - Focussed on district/precinct/neighbourhood scale covering } \\
\text { blocks, plots, typologies, etc. } \\
\underline{\text { Macro level-Generally at city scale covering political control, socio-cultural }} \\
\text { context, incremental nature of economy, contemporary trends, etc. }\end{array}$ \\
\hline
\end{tabular}

Several urban morphological variables of cities reflect the evolution and the development history during different period of time. Analysis of urban morphology assists in better collective understanding of the urban form and its structure while facilitating decision making process and structures of management. The morphological measures and the related analysis could be applied to formulate frameworks for more adaptive and resilient urban forms with regard to environmental concerns, economic viability and social acceptability. Neighborhoods, that are in transition need focused approach and well-articulated processes that would enable them to be compact, coordinated, connected and socially inclusive. The place based approach provide an opportunity for improving efficiencies in providing informed growth directions to areas that can support contemporary development while leveraging the benefits of established urban structure and system. It also indicates new opportunities for a better production of urban spaces with due consideration of the intermediate scale of urban form. With increasing deterioration in the efficiency of urban forms 
across majority of metropolis, the study attempts to offer certain insights on formulating key morphological measures that can be derived and applied objectively to several other neighborhoods with specific adoptions and modifications to elevate the quality of urban living.

\section{References}

1. Conzen, M.R.G (1960). Alnwick, Northumberland: a study in town-plan analysis G. Philip

2. Hillier. B.\& Hanson, J. (1984). The social logic of space. Cambridge University Press, Cambridge

3. MHUPA, "National Policy for Urban Street Vendors”, Ministry of Housing and Urban Poverty Alleviation. [Online]. Available mhupa.gov.in/policies, Accessed on 19th June 2018.

4. Rasmussen, S.E. (1969). Towns and buildings. Cambridge, The MIT Press.

5. R. Jhabvala, "Roles and perceptions of street vendors”, A symposium on reconciling people's livelihood and urban governance.

6. S. K. Bhowmik, "National policy for street vendors", Economic and Political Weekly, vol. 38, no. 16, pp. 1543-1546, 2003.

7. UNESCO.(2016). Global Report on Culture and Sustainable Urban Development: Report for UN Habitat III.Paris: UNESCO 